\title{
Trends in the Frequency of High Relative Humidity over China: 1979-2012*
}

\author{
RUI MAO AND DAO-YI GONG \\ State Key Laboratory of Earth Surface Processes and Resource Ecology, Beijing Normal University, Beijing, China \\ TIANBAO ZHAO \\ Key Laboratory of Regional Climate-Environment Research for East Asia, Institute of Atmospheric Physics, \\ Chinese Academy of Sciences, Beijing, China \\ WENSHAN WANG \\ Department of Earth System Science, University of California, Irvine, Irvine, California \\ JING YANG \\ State Key Laboratory of Earth Surface Processes and Resource Ecology, Beijing Normal University, Beijing, China
}

(Manuscript received 9 December 2014, in final form 9 September 2015)

\begin{abstract}
High relative humidity $(\mathrm{HRH})$ is defined as a relative humidity of at least $80 \%$, which is often associated with the occurrence of cloud layers. Thus, the frequency of HRH and its changes in the troposphere may be related to the occurrence frequency of cloud layers and their changes. In this study, trends in the frequency of HRH (defined as days with relative humidity $\geq 80 \%$ ) over China from the surface to the midtroposphere ( $\geq 400 \mathrm{hPa}$ ) from 1979 to 2012 were analyzed using a homogenized humidity dataset for spring (March-May), summer (June-August), autumn (September-November), and winter (December-February). The results for the ground level indicate decreasing trends at most stations in southeastern China in spring and in northern China in summer. In the lower troposphere $(850$ and $700 \mathrm{hPa})$, most stations over China exhibit positive trends in summer, autumn, and winter. For the midtroposphere $(500-400 \mathrm{hPa})$, increasing trends dominate over China in spring, summer, and autumn. Finally, six reanalysis datasets, the NCEP-NCAR, NCEP-DOE, CFSR, ERA-Interim, MERRA, and JRA-55 datasets, were compared with the observed increasing trends in HRH frequency in the low-to-middle troposphere. Similar increasing trends in HRH frequency in the reanalysis datasets and the homogenized humidity data are observed in certain seasons and for certain regions. These results are consistent with the increasing low-to-middle cloud amounts in recent decades.
\end{abstract}

\section{Introduction}

Relative humidity $(\mathrm{RH})$ reflects the vapor saturation level in the atmosphere. High RH (HRH) is an indicator of possible cloud formation and precipitation, and it strongly affects atmospheric visibility by influencing cloud

\footnotetext{
* Supplemental information related to this paper is available at the Journals Online website: http://dx.doi.org/10.1175/JCLI-D-1400840.s1.

Corresponding author address: Rui Mao, State Key Laboratory of Earth Surface Processes and Resource Ecology, Beijing Normal University, Beijing, China.

E-mail: mr@bnu.edu.cn
}

height and the formation of fog (Sundqvist 1978; Price and Wood 2002; Wright et al. 2010). Moreover, RH is related to convection, subsidence, and horizontal air advection, often serving as a better description of water vapor and cloud feedback than specific humidity (e.g., Xie et al. 2011; Ruzmaikin et al. 2014). There have been numerous previous humidity studies; most of this research has examined the climatological pattern of $\mathrm{RH}$ and the longterm trend in the mean RH. However, relatively fewer investigations have examined RH extremes and longterm RH extreme trends in the context of climate change.

More research has recognized linear trends in global and regional $\mathrm{RH}$ in the troposphere (e.g., van Wijngaarden and Vincent 2004; Dai 2006; Willett et al. 2008; Simmons et al. 2010; Xie et al. 2011; Zhao et al. 
2012). On a global scale, trends in RH, calculated from synoptic data from 1976 to 2005 from ships and buoys and more than 15000 land stations, are very small at the surface (Dai 2006). This finding was supported by the Met Office Hadley Centre and Climatic Research Unit Global Surface Humidity dataset (HadCRUH), suggesting that trends in $\mathrm{RH}$ are small and not significant at the global scale, in the Northern Hemisphere, or in the tropics (Willett et al. 2008). However, in a suite of reanalysis datasets that included the ERA-40, ERAInterim, HadCRUH (and its extended version HadCRUHext), and JRA-25 and JMA Climate Data Assimilation System (JCDAS) datasets, a steep decrease in $\mathrm{RH}$ was recognized over low-latitude and midlatitude continental areas. This inconsistency is likely a consequence of an inconsistency between the reanalysis datasets and the radiosonde measurements (Andersson et al. 2007; Simmons et al. 2010). In addition, regarding the lower and middle troposphere, changes in the global $\mathrm{RH}$ have been the subject of substantial debate as a result of instrumental limitations. Paltridge et al. (2009) found using the NCEP reanalysis data that the global RH has decreased over the last three or four decades at and above $850 \mathrm{hPa}$, which does not support the notion that the $\mathrm{RH}$ at any given height in the troposphere has remained fairly constant under the influence of global warming; this latter assertion had been revealed in general circulation climate models and was based on a homogenized global twice-daily dewpoint depression dataset (Dai et al. 2011). Moreover, trends in regional RH at the surface and high levels have been investigated (van Wijngaarden and Vincent 2004; Hosseinzadeh Talaee et al. 2012; Xie et al. 2011; Zhao et al. 2012). For example, the RH in Canada was analyzed using data over the period 1953-2003; the results suggested a substantial decrease in the $\mathrm{RH}$ in winter and spring (van Wijngaarden and Vincent 2004). The annual RH in Iran has increased by $1.03 \%$ and $0.28 \%$ decade $^{-1}$ in the northern and southern coastal regions of the country, respectively ( $\mathrm{P}$. Hosseinzadeh Talaee et al. 2012). In China, the tropospheric annual mean RH has exhibited only small variations, with weak upward trends $\left(0.2 \%-1.0 \%\right.$ decade $\left.^{-1}\right)$ from 850 to $300 \mathrm{hPa}$ (primarily in summer) and slight downward trends $\left(-0.2 \%-0.4 \%\right.$ decade $\left.^{-1}\right)$ in the lower troposphere in spring (Xie et al. 2011; Zhao et al. 2012).

Many studies have evaluated the linear trends in the average $\mathrm{RH}$ at the surface and in the lower-to-middle troposphere; however, few works have examined $\mathrm{RH}$ extremes in the troposphere. High RH values exceeding $84 \%$ are associated with cloudy layers as a rawinsonde penetrates a given layer (Webster and Stephens 1984; Zhang et al. 2010). Many studies have used high RH values to discriminate cloud vertical structure, including cloud-top and cloud-base heights, cloud layer thickness, and the characteristics of multilayered clouds (e.g., Wang and Rossow 1995; Wang et al. 2000; Zhang et al. 2010; Zhou and Ou 2010; Zhang et al. 2012; Cai et al. 2014). For example, some authors have identified cloud-layer base and top locations based on three criteria: 1) maximum $\mathrm{RH}$ exceeding $87 \%, 2)$ minimum $\mathrm{RH}$ of at least $84 \%$, and 3) RH jumps exceeding $3 \%$ at the cloud-layer top and base (Wang and Rossow 1995; Zhang et al. 2010; Zhang et al. 2012). Cai et al. (2014) compared L-band sounding data and CloudSat data and found that the accuracy of cloud discrimination can reach $81 \%$ by setting the RH threshold to $75 \%$. Based on the aforementioned studies, HRH in the troposphere, particularly in the lower and middle troposphere, is tightly associated with the occurrence of cloud layers. In addition, some authors have analyzed the potential formation of clouds using HRH as an indicator (e.g., Haag et al. 2003; Chakraborty and Maitra 2012). Thus, we hypothesized that variations in the frequency of HRH may be related to changes in the occurrence frequency of cloud layers and may be a potential measurement to represent cloud formation.

In this study, on the basis of a homogenized radiosonde humidity dataset (Dai et al. 2011), trends in the frequency of HRH from the surface to the midtroposphere from 1979 to 2012 were examined over China. This work may provide evidence for changes in tropospheric water vapor extremes and variations in cloud formation and potential and in cloud layers in a warming background. To support the findings derived from the homogenized humidity dataset, six reanalysis datasets were examined to detect trends in the HRH frequency in the troposphere. These reanalysis datasets included the National Centers for Environment Prediction (NCEP)-National Center for Atmospheric Research (NCAR) reanalysis (NCEP-1) (Kalnay et al. 1996; Kistler et al. 2001), the NCEP-U.S. Department of Energy AMIP phase 2 (AMIP-II) reanalysis (NCEP-2) (Kanamitsu et al. 2002), the Climate Forecast System Reanalysis (CFSR) (Saha et al. 2010), the European Centre for Medium-Range Weather Forecasts interim reanalysis (ERA-Interim) (Dee et al. 2011; Simmons et al. 2010), the Modern-Era Retrospective Analysis for Research and Applications (MERRA), which was developed by the National Aeronautics and Space Administration (Rienecker et al. 2011), and the Japanese 55-year Reanalysis Project (JRA-55) (Ebita et al. 2011).

This paper is structured as follows. Section 2 briefly describes the data and methods used. In section 3, spatial and vertical changes in the frequency of $\mathrm{HRH}$ are analyzed using the homogenized humidity dataset. In addition to the results derived using the homogenized 
humidity dataset, the results obtained using the six reanalysis datasets are also given in section 3 . In section 4, spatial and vertical features of the trends in HRH frequency are shown for the homogenized humidity dataset and the six reanalysis datasets. Subsequently, long-term trends in cloud amount derived from cloud observations and the six reanalysis datasets are analyzed in section 5 to support the findings on the trends in HRH frequency over China. In section 6, several potential issues, including changes in the frequency distribution of $\mathrm{RH}$, the effect of long-term variations in rainy days, and discontinuity in the general radiosonde data, are discussed. Finally, a summary is provided in section 7. During analysis, the effect of diurnal variations on the changes in the mean and in the trend of HRH frequency was considered. Because of the similarity of the results for 0000 and 1200 UTC, only the results at 0000 UTC are displayed herein for simplicity.

\section{Data and methods}

\section{a. Data}

In this study, a homogenized humidity dataset (up to $400 \mathrm{hPa}$ ) encompassing the period 1979-2012 was analyzed. This dataset includes information regarding pressure, air temperature, and dewpoint depression (DPD) from 158 Chinese stations. Based on this dataset, RH was calculated by using a formula with respect to water (ice) when air temperature was above (below) $0^{\circ} \mathrm{C}$, and then changes in the $\mathrm{HRH}$ frequency from the surface to the midtroposphere were determined. The homogenized humidity dataset included twice-daily observations at 0000 and 1200 UTC and was produced based on radiosonde data from Chinese stations. The original humidity variable dataset contained different discontinuities resulting from sonde sensor changes. Most early radiosonde hygrometers were considered unreliable under cold conditions, and there were fewer DPD reports in early observations when the temperature was below $-40^{\circ} \mathrm{C}$ (Remsberg et al. 2000). In addition, different radiosonde hygrometers have different sensitivities and response times that often lead to different measurement errors under wet and dry conditions (Dai et al. 2011). Dai et al. (2011) used two statistical tests to detect such changes: a variant of the Kolmogorov-Smirnov test for changes in distributions and the penalized maximal $F$ test for mean shifts in the occurrence frequency for different DPD bins. Before applying adjustments, homogeneous sampling was first minimized by estimating missing DPD reports for cold $\left(T<-30^{\circ} \mathrm{C}\right)$ conditions based on an empirical relationship with the measured air temperature. The sampling-adjusted
DPDs were subsequently adjusted using a quantilematching algorithm to ensure that the earlier segments had histograms comparable to that of the most recent segment. Based on this homogenized humidity dataset, Zhao et al. (2012) determined the linear trends in the tropospheric humidity during the period 1970-2008 over China and found that the homogenized dataset outperformed the raw data when describing the tropospheric humidity changes due to its enhanced temporal and spatial coherence.

In addition, changes in cloud amount were examined to compare with the variations in the frequency of HRH over China, which were obtained from daily surface reports collected by the China Meteorological Administration. This cloud information, including total cloud amount and low-to-middle cloud amount, were collected from land stations from 1979 to 2005. Although the number of stations in this cloud dataset exceeded 1100 , only approximately 200 stations were retained after data quality control because of numerous missing and discontinuous records in this dataset.

Finally, six reanalysis datasets, including the CFSR, ERA-Interim, JRA-55, MERRA, NCEP-1, and NCEP2 datasets, were employed to detect the trends in the frequency of HRH in the lower and middle troposphere. The aim of analyzing reanalysis datasets was to examine whether these reanalysis datasets involving synoptic records supported the findings derived from the homogenized humidity dataset and whether there were any differences that shed light on the deficiencies in the reanalysis datasets. These reanalysis datasets have been widely applied in many previous studies-for example, to evaluate in situ measurements over the Tibetan Plateau (Wang and Zeng 2012; Bao and Zhang 2013) and to examine low-frequency variability and trends in temperature (Simmons et al. 2014). Details regarding each reanalysis product can be easily found in the corresponding references and are not repeated here. These reanalysis datasets have different temporal and spatial resolutions. The CFSR was available for the period 1979-2009. The JRA-55 dataset was provided from 1979 to 2011. For the other reanalysis datasets, the ERA-Interim, MERRA, NCEP-1, and NCEP-2, the period spanned from 1979 to 2012. The trends in the frequency of HRH were calculated using all of the data in each reanalysis dataset. To be consistent with the homogenized humidity data, twice-daily data at 0000 and 1200 UTC in these reanalysis datasets were used and only data at $850,700,500$, and $400 \mathrm{hPa}$ were analyzed. Since some of reanalysis datasets contain RH data at the ground level, the surface data in the reanalysis datasets were not examined. In addition, trends in cloud amount in each reanalysis dataset were observed and were 
compared to that from surface observations. The reanalysis datasets are classified into two groups: one containing monthly total cloud amount (ERA-Interim, JRA-55, NCEP-1, and NCEP-2) and the other providing monthly low cloud amount and medium cloud amount (CFSR, ERA-Interim, JRA-55, and MERRA).

\section{b. Analysis method}

In this study, $\mathrm{HRH}$ was defined as a $\mathrm{RH}$ value of at least $80 \%$, and $\mathrm{HRH}$ days were counted as the frequency of HRH in the homogenized humidity dataset and the six reanalysis datasets. Some authors have indicated a $\mathrm{RH}$ threshold of $84 \%-87 \%$ for recognizing cloud levels (e.g., Wang and Rossow 1995; Zhang et al. 2010; Zhou and Ou 2010). For comparison, L-band sounding data and CloudSat data analyses have shown that the accuracy of cloud discrimination can reach $81 \%$ using a RH threshold of $75 \%$; based on bias and threat scores, a RH threshold of $81 \%$ results in the highest threat score for discriminating clouds (Cai et al. 2014). Therefore, in this study, a RH threshold of $80 \%$ was used to determine HRH events. For a given level, when the RH was found to be at least $80 \%$, a HRH day was recognized at this level. Following this definition, HRH days were counted for each year at each level for all four seasons; the average and trend of these HRH frequency time series were calculated. Similarly, $\mathrm{HRH}$ frequencies in the lower and middle troposphere were determined from six reanalysis datasets, which were also defined using the same RH threshold ( $\geq 80 \%$ ), and the average and the trend of the HRH frequency time series were calculated. Although the determination of the $80 \% \mathrm{RH}$ threshold is arbitrary, it could help to yield a more confident analysis of trend in HRH frequency compared to strict criteria for the RH threshold, such as $90 \%$, that would cause few frequencies of HRH over several years.

Because of missing records in the homogenized humidity data, data quality control was essential for the analysis. The data quality control process was as follows. 1) For a given season and for a given station, when the number of missing records in the HRH time series accounted for more than $10 \%$ of the total number of records, all records in this season were removed; the $\mathrm{HRH}$ frequency in the given season was assumed to be missing. Following these criteria, HRH frequency time series for every station in a given season were obtained. 2) For calculating the mean and trend in the HRH frequency, the number of missing records in a given HRH frequency time series was counted. When the percentage of missing records was at least $20 \%$, the station was omitted from further analysis. 3) After these steps, the number of zeros and missing records in the time series were also considered; when the zeros and the missing records accounted for more than $40 \%$ of the total number of records at a given station, the station was excluded from the calculation of the HRH frequency trend because too many zeros and missing records in the time series may result in an uncertain result. Note that a zero frequency in HRH means that all of the RH values in a season are less than $80 \%$. For instance, most of the $\mathrm{RH}$ values are within a range of $10 \%-50 \%$ at $850 \mathrm{hPa}$ during summer for station $51243\left(54.6^{\circ} \mathrm{N}, 84.8^{\circ} \mathrm{E}\right)$; therefore, there are many zero frequencies of $\mathrm{HRH}$ at $850 \mathrm{hPa}$ during summer for this station during the period 1979-2012. After data quality control, the number and location of the selected stations varied as a function of the level between the surface and the midtroposphere and according to the season. There were approximately 80 stations selected for the ground level and $80-110$ stations selected for the lower and middle troposphere. The selected stations for the lower and middle troposphere included most of the stations selected for the ground level. It is worth noting that there were very few records of $\mathrm{RH}$ at 850 and $700 \mathrm{hPa}$ over southwestern China, particularly over the Tibetan Plateau, because of topographic reasons. Therefore, few stations were selected for southwestern China at 850 and $700 \mathrm{hPa}$ and only the ground level and the midtroposphere (500 and $400 \mathrm{hPa}$ ) were examined for southwestern China. In addition, this quality control was utilized again to filter out the cloud data. However, in the first step of quality control (i.e., counting the number of missing records in the time series for cloud amount), the threshold was set to $20 \%$ to account for missing records in a given season resulting from the scarcity of cloud observations.

In this study, the least squares linear regression method was employed to calculate trends. Since there are few stations over southwestern China at 850 and $700 \mathrm{hPa}$, the $\mathrm{HRH}$ frequencies at these levels were not calculated in either the homogenized humidity dataset or the reanalysis datasets. In addition, in the discussion section, the frequency distributions of all RH values were analyzed for each level from the surface to the midtroposphere. All four seasons were analyzed, spring (March-May), summer (June-August), autumn (September-November), and winter (December through January and February of the following year).

\section{Climatological patterns of HRH frequency calculated using the homogenized humidity data and the six reanalysis datasets}

\section{a. Spatial distribution of climatological $\mathrm{HRH}$ frequency}

Figure 1 shows the spatial distribution of the mean $\mathrm{HRH}$ frequency in summer. At the ground level, the 

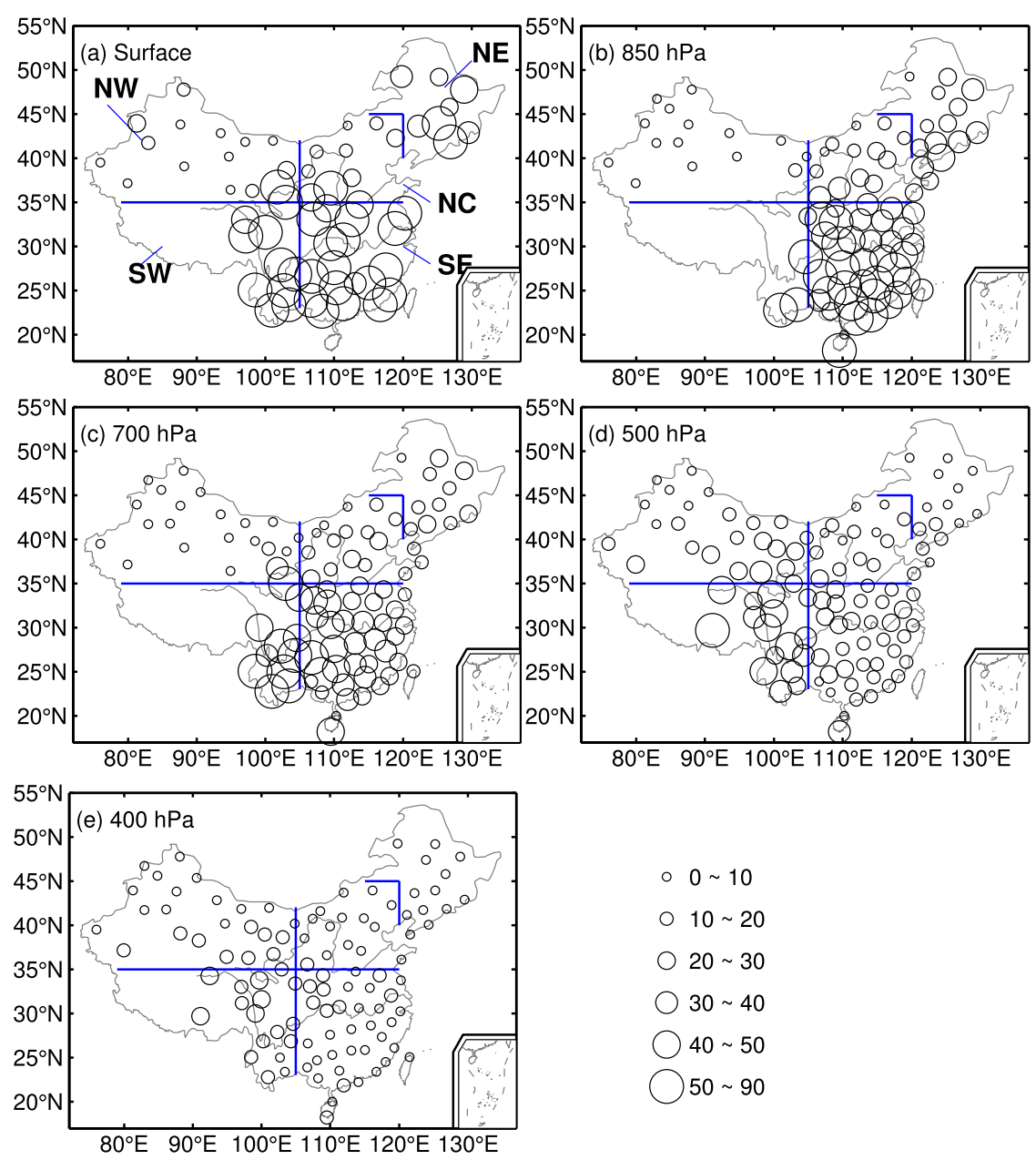

FIG. 1. Spatial distribution of mean HRH frequency in summer over China: (a) surface, (b) $850 \mathrm{hPa}$, (c) $700 \mathrm{hPa}$, (d) $500 \mathrm{hPa}$, and (e) $400 \mathrm{hPa}$. Unit is days per summer. The five regions in (a) include northeastern China (NE), northern China (NC), southeastern China (SE), southwestern China (SW), and northwestern China (NW).

highest HRH frequencies are greater than 50 days per summer over southeastern China and east of southwestern China, which are followed by approximately 40 days per summer in northeastern China. The low HRH frequencies are approximately 30 days per summer over northern China (in the central part of eastern China and at the north edge of the East Asian summer monsoon region) and 10 days per summer over northwestern China. In the lower troposphere (850 and $700 \mathrm{hPa}$ ), the highest HRH frequencies are approximately 40-50 days per summer over southeastern China, and the higher ones are 20-40 days over northeastern and northern China; the lowest ones are less than 10 days per summer over northwestern China. In the midtroposphere, the HRH frequencies over southwestern China are much higher than over other regions in China, with values of approximately 40 days (20 days) at
$500 \mathrm{hPa}(400 \mathrm{hPa})$ compared to 20 days (less than 10 days) over other regions. The spatial distribution of the climatological HRH frequency during spring, autumn, and winter resembles that in summer (not shown). In the lower troposphere (surface, $850 \mathrm{hPa}$, and $700 \mathrm{hPa}$ ), the HRH frequencies are high over the south of China and are low over the north of China; for the midtroposphere, the HRH frequencies are comparable everywhere, with values of less than 20 days per season over China. Compared to summer, the HRH frequencies over northeastern and northern China are lower in other seasons from the surface to the midtroposphere, and the HRH frequencies over southwestern China decrease in amount in the midtroposphere during other seasons. The spatial changes in climatological HRH frequency are in accordance with that for mean RH. The mean $\mathrm{RH}$ values in the lower and middle troposphere 

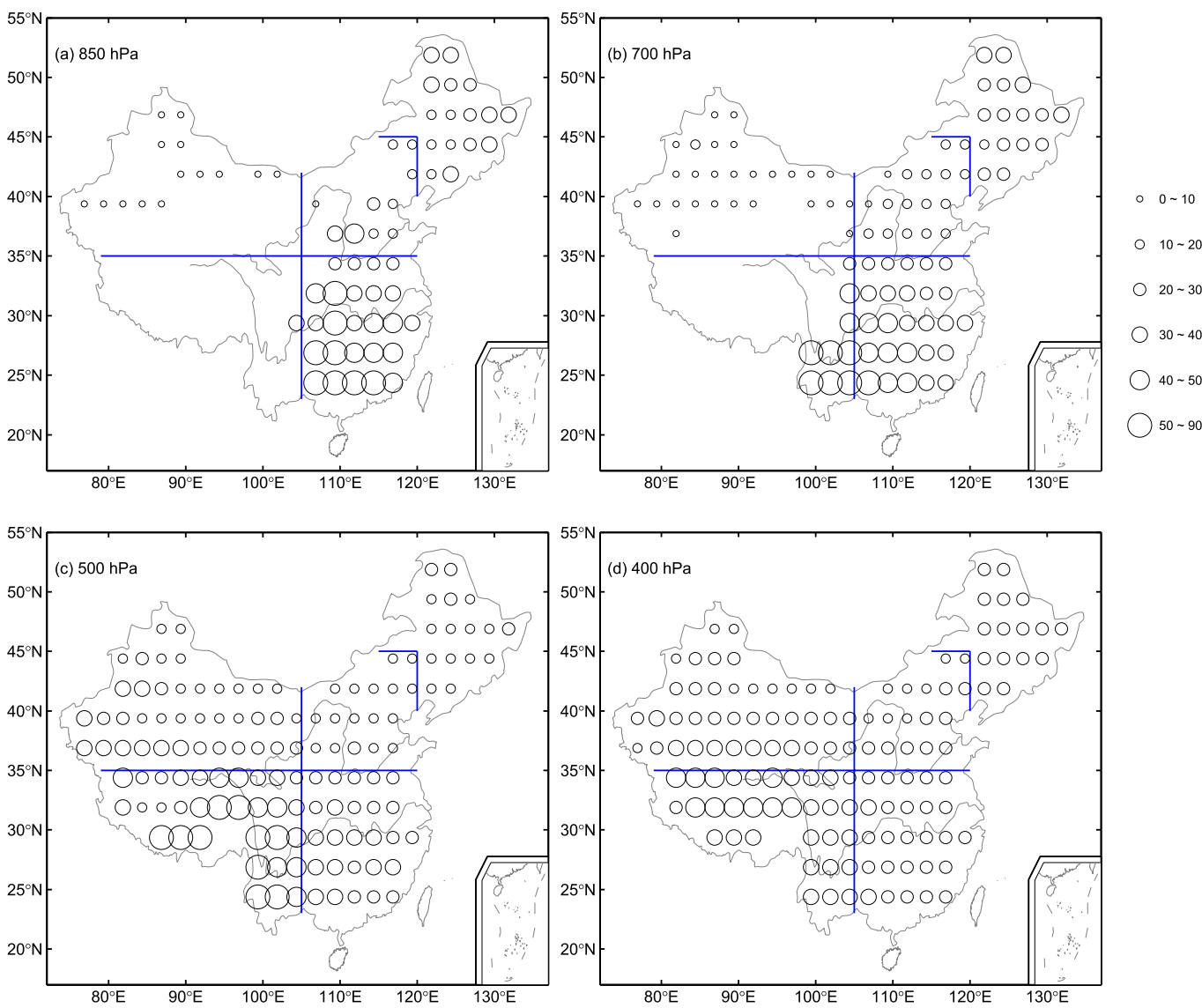

FIG. 2. As in Fig. 1, but derived from the MERRA reanalysis dataset: (a) 850, (b) 700, (c) 500, and (d) $400 \mathrm{hPa}$. Unit is days per summer.

are higher over southern China than those over northern China. Influenced by the East Asian monsoon, the mean RH exhibits very large seasonal and spatial variations, with peaks in summer and in southern China, respectively (Zhai and Eskridge 1997). Therefore, the mean RH over China is higher in summer than in other seasons and over southern China compared to over northern China, which may determine the spatial and seasonal variations in the climatological HRH frequency (Xie et al. 2011).

Similarly, the spatial distributions of climatological HRH frequency derived from six reanalysis datasets were analyzed. These reanalysis datasets exhibit similar spatial distributions of climatological HRH frequency during the four seasons, although the amounts of the climatological HRH frequencies are not exactly the same among these reanalysis datasets. Here, the results derived using the MERRA reanalysis dataset are displayed to depict the spatial distribution of the climatological HRH frequency and to compare with that in the homogenized humidity data (Fig. 2 for summer; figures not shown for other seasons). In general, the MERRA result reproduces the distribution feature of the climatological HRH frequency derived using the homogenized humidity dataset. During summer in the lower troposphere ( 850 and $700 \mathrm{hPa})$, the highest $\mathrm{HRH}$ frequencies are found over southeastern China and east of southwestern China, which are followed by slightly lower frequencies over northeastern China. In the midtroposphere (500 and $400 \mathrm{hPa}$ ), the $\mathrm{HRH}$ frequencies are higher over southwestern China than over other regions. During spring, autumn, and winter, the climatological HRH frequencies exhibit similar spatial patterns as that in summer in the lower troposphere $(850$ and $700 \mathrm{hPa}$ ), that is, high $\mathrm{HRH}$ frequencies over southeastern China and east of southwestern China and low frequencies over other regions. For the midtroposphere at $500 \mathrm{hPa}(400 \mathrm{hPa})$, the spatial distribution of climatological HRH frequencies is similar in spring and autumn, with high values over southern (western) China that are also found in the homogenized humidity dataset. During winter, high HRH frequencies are observed over northwestern China at $400 \mathrm{hPa}(\sim 25$ days per winter); however, in the homogenized humidity dataset, 
the HRH frequencies are comparable over China, and they are less than 10 days per winter.

\section{b. Vertical profile of climatological HRH frequency}

To easily comprehend the vertical changes in the climatological HRH frequencies in the troposphere, vertical profiles of climatological HRH frequencies derived from the homogenized humidity dataset and the six reanalysis datasets were analyzed. In general, except in northwestern China, the climatological HRH frequencies are higher in the lower troposphere than in the midtroposphere over China during the four seasons; the HRH frequencies decrease more rapidly and to a greater extent over southeastern China than over other regions. Figure 3a shows the vertical profiles of the climatological HRH frequency in the troposphere in summer, which are derived by the homogenized humidity dataset. At the ground level, the climatological HRH frequencies are high over southeastern and southwestern China ( $\sim 70$ days per summer), followed by 40 days per summer over northeastern China, 30 days per summer over northern China, and approximately 15 days per summer over northwestern China. In the lower troposphere ( 850 and $700 \mathrm{hPa})$, the climatological HRH frequencies decrease by nearly half over southeastern and northeastern China compared to those at the surface; in contrast, those over northern and northwestern China exhibit a slight decrease from the surface to $700 \mathrm{hPa}$. In the midtroposphere $(500$ and $400 \mathrm{hPa}$ ), the HRH frequency is high over southwestern China ( 40 days per summer at $500 \mathrm{hPa}$ and 20 days per summer at $400 \mathrm{hPa}$ ), but other regions are accompanied by low HRH frequencies of less than 20 days per summer. The HRH frequencies during spring, autumn, and winter show similar vertical profiles compared to summer (i.e., high values in the lower troposphere and low values in the midtroposphere). However, compared to summer, there are reductions in the climatological HRH frequencies over northeastern China and northern China during spring, autumn, and winter. In addition, the climatological HRH frequencies over southwestern China show different patterns in the midtroposphere between summer and the other seasons; during summer, the climatological HRH frequency over southwestern China is higher than over other regions, but it becomes comparable during spring, autumn, and winter (not shown).

In addition, vertical profiles of the climatological $\mathrm{HRH}$ frequency derived from six reanalysis datasets were compared with the homogenized humidity dataset (Figs. 3b-g). On one hand, the six reanalysis datasets show similar vertical profiles of HRH frequency at 850 and $700 \mathrm{hPa}$ for different regions in China. The climatological HRH frequencies are highest over southeastern China and are higher over northeastern and northern China, followed by lower values over northwestern China. From 850 to $700 \mathrm{hPa}$, the climatological HRH frequencies increase over northwestern China and weakly decrease over other regions. On the other hand, in the midtroposphere (500 and $400 \mathrm{hPa}$ ), the climatological HRH frequencies at each level are comparable for all regions during the four seasons, except in southwestern China where the climatological HRH frequencies are higher than the other regions during summer. In addition, the climatological HRH frequencies derived from the CFSR, ERA-Interim, JRA-55, and MERRA datasets show weak increases over northern China from 500 to $400 \mathrm{hPa}$, but NCEP-1 and NCEP-2 present an opposite change in the climatological HRH frequency for these regions, which is also observed in the homogenized humidity dataset. On the basis of the above results, the six reanalysis datasets better reproduce the vertical distribution of climatological HRH frequency observed in the homogenized humidity dataset.

\section{Trends in HRH frequency calculated using the homogenized humidity data and the six reanalysis datasets}

\section{a. Spatial distribution of trends in the HRH frequency}

Figure 4 shows the spatial distribution of HRH frequency trends for different levels in the lower and middle troposphere during summer. The stations are characterized by decreasing trends at the ground level and increasing trends in the lower and middle troposphere. At the ground level, nearly two-thirds of the stations are characterized by decreasing trends over China; the decreasing-trend stations are primarily located over northern China. In the lower troposphere $(850$ and $700 \mathrm{hPa})$, around two-thirds of the stations show increasing trends, which are significant at the $95 \%$ confidence level over southeastern China and northeastern China. For the midtroposphere (500 and $400 \mathrm{hPa}$ ), more than $85 \%$ of the stations present increasing trends over China, half of which are significant at the $95 \%$ confidence level and are mainly located over southwestern China and southeastern China. Compared to summer, the spatial distributions of trends in the HRH frequencies show different features in spring, autumn, and winter (not shown). During spring, decreasing trends prevail at the ground level. However, they become increasing trends over northeastern China and over northwestern China in the lower troposphere. In the midtroposphere, increasing trends are dominant over China, with significant trends 
(a) Radiosonde data

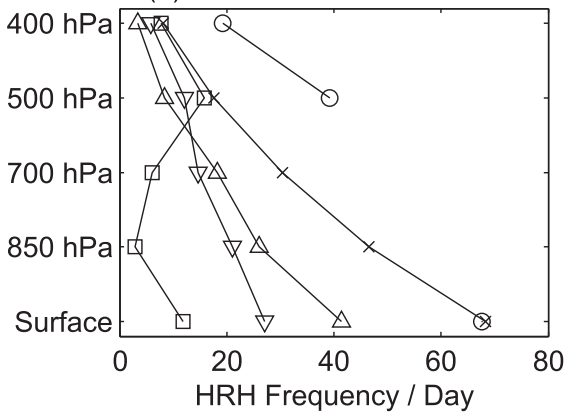

(c) Era-Interim

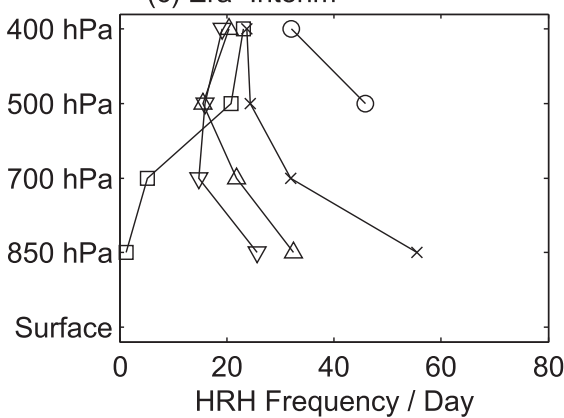

(e) MERRA

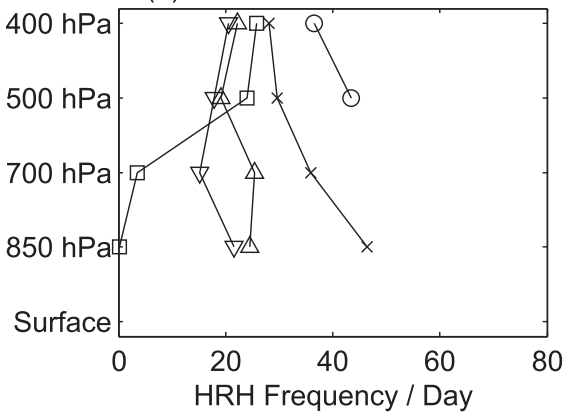

(g) NCEP II

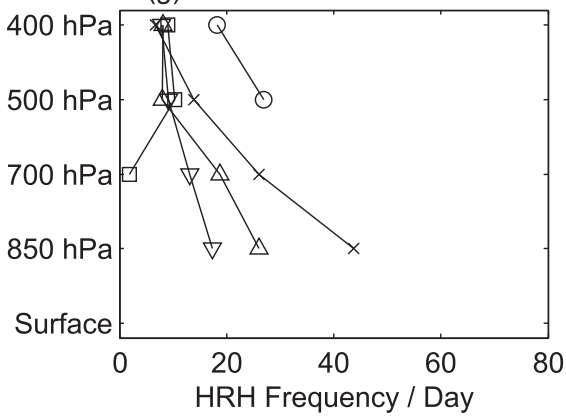

FIG. 3. Vertical profiles of mean HRH frequency in summer computed from radiosonde data and six reanalysis datasets over the NE, NC, SE, SW, and NW regions (see Fig. 1a for regions): (a) radiosonde, (b) CFSR, (c) ERA-Interim, (d) JRA-55, (e) MERRA, (f) NCEP-1, and (g) NCEP-2. Values for the ground level are not shown for six reanalysis datasets because they are not provided by the MERRA and do not really exist for topographic reasons in other reanalysis datasets. In addition, values over southwestern China are not shown at 850 and $700 \mathrm{hPa}$ for radiosonde and the reanalysis datasets because the stations or grid points at these levels are located southeast of the SW region. Unit is days per summer. (b) CFSR

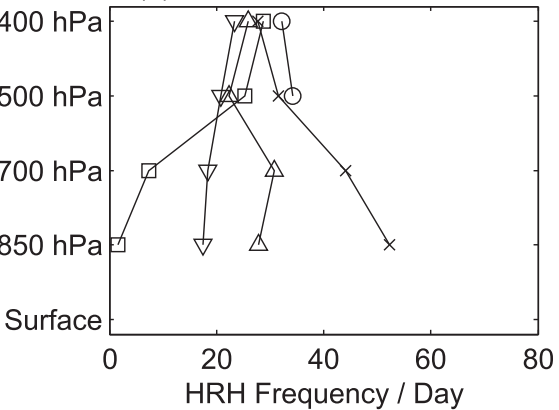

(d) JRA-55

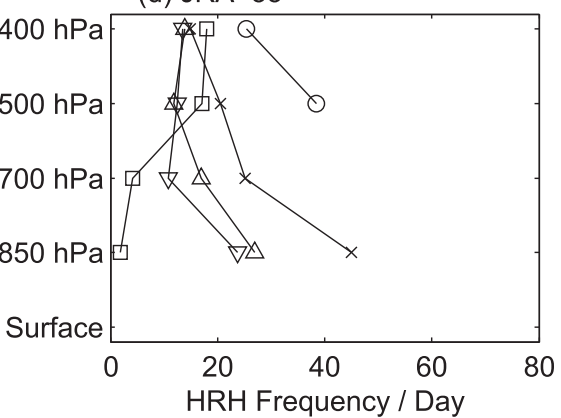

(f) NCEP I

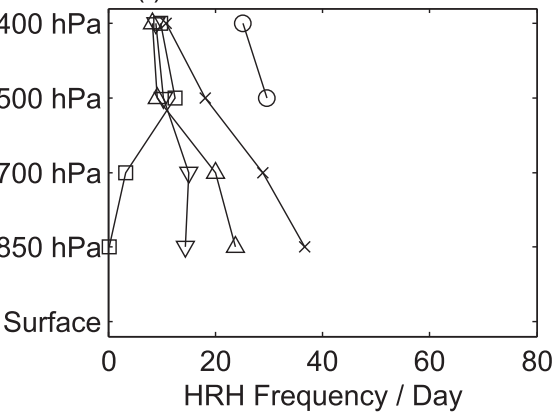



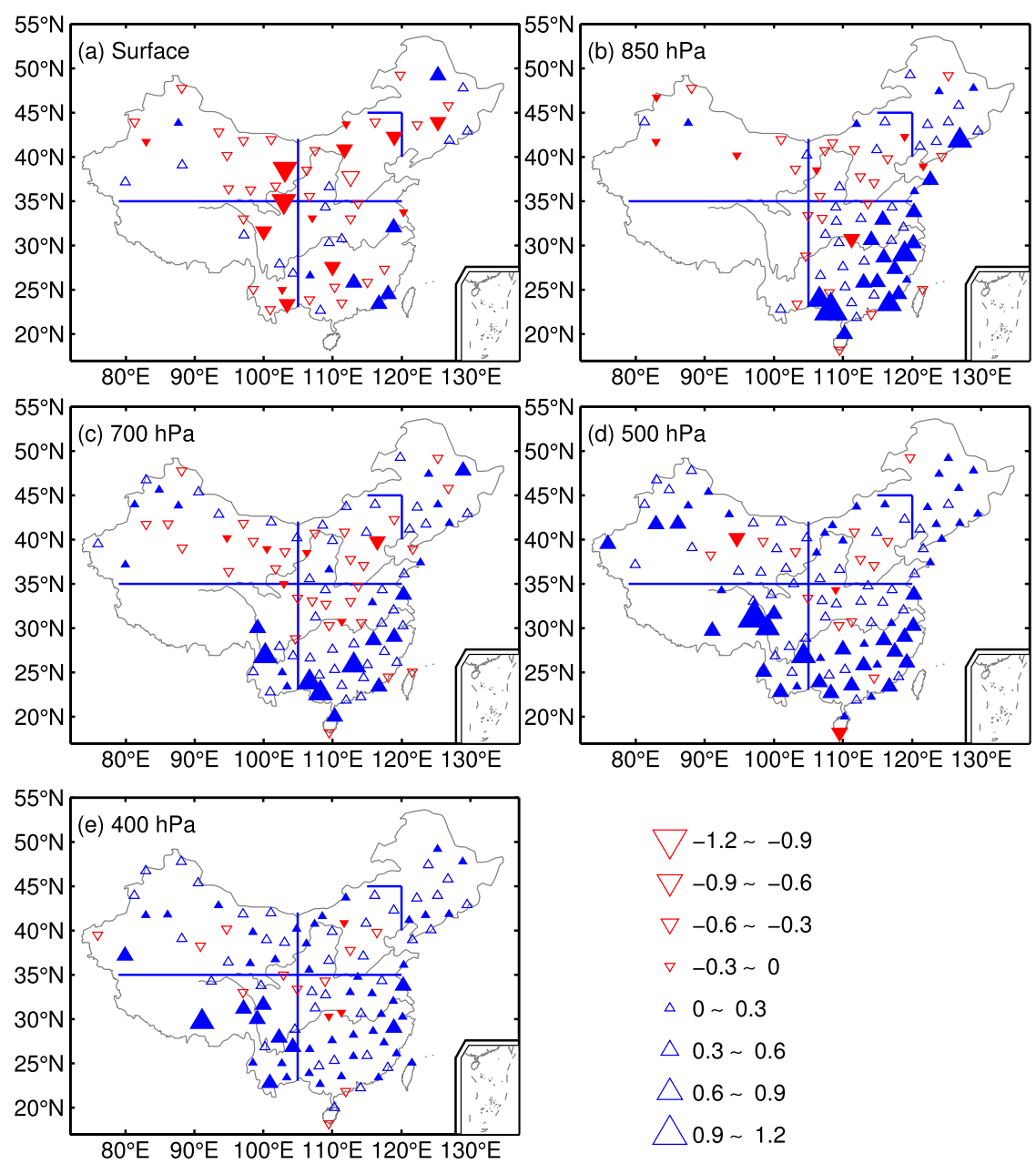

$$
\begin{aligned}
& \nabla-1.2 \sim-0.9 \\
& \nabla-0.9 \sim-0.6 \\
& \nabla-0.6 \sim-0.3 \\
& \nabla-0.3 \sim 0 \\
& \triangle 0 \sim 0.3 \\
& \triangle 0.3 \sim 0.6 \\
& \triangle 0.6 \sim 0.9 \\
& \triangle 0.9 \sim 1.2
\end{aligned}
$$

FIG. 4. Spatial distribution of HRH frequency trends in summer over China: (a) surface, (b) $850 \mathrm{hPa}$, (c) $700 \mathrm{hPa}$, (d) $500 \mathrm{hPa}$, and (e) $400 \mathrm{hPa}$. Unit is days per summer. Filled markers are significant at the $95 \%$ confidence level.

exceeding the $95 \%$ confidence level over southwestern China. During autumn, increasing trends are overwhelming over China in the lower and middle troposphere. For winter, increasing trends are only observed in the lower troposphere, and there are nonuniform spatial distributions of trends in the HRH frequency in the midtroposphere. On the basis of the above analyses, the homogenized humidity dataset reveals an increase in the HRH frequency in the midtroposphere (the lower troposphere) during spring, summer, and autumn (summer, autumn, and winter) over China. This continental scale of increasing $\mathrm{HRH}$ frequencies in the lower and middle troposphere is supported by increasing trends of the mean $\mathrm{RH}$ in the lower and middle troposphere over China. Zhao et al. (2012) indicated that wet anomalies are recognized after the mid-1980s at $700-300 \mathrm{hPa}$, while there are no obvious trends below $700 \mathrm{hPa}$. RH trends show both positive (mostly in summer and above $850 \mathrm{hPa}$ ) and negative (from winter to spring in the lower troposphere) values.

Compared to the homogenized humidity dataset, the spatial distributions of the HRH frequency trends in six reanalysis datasets were analyzed. Here, the MERRA reanalysis dataset is taken as an example to show the spatial distribution of trends in the reanalysis dataset because its result is more consistent with that derived from the homogenized humidity dataset than the other reanalysis datasets. During summer, there are increasing trends over southeastern China at $850 \mathrm{hPa}$ and over all of China at $700 \mathrm{hPa}$, which reproduces the spatial pattern of the HRH frequency trends in the homogenized humidity dataset. In the midtroposphere, however, the MERRA reanalysis dataset shows increasing trends over northwestern China and decreasing trends over other regions, which is different from the prevailing increasing trends in the 


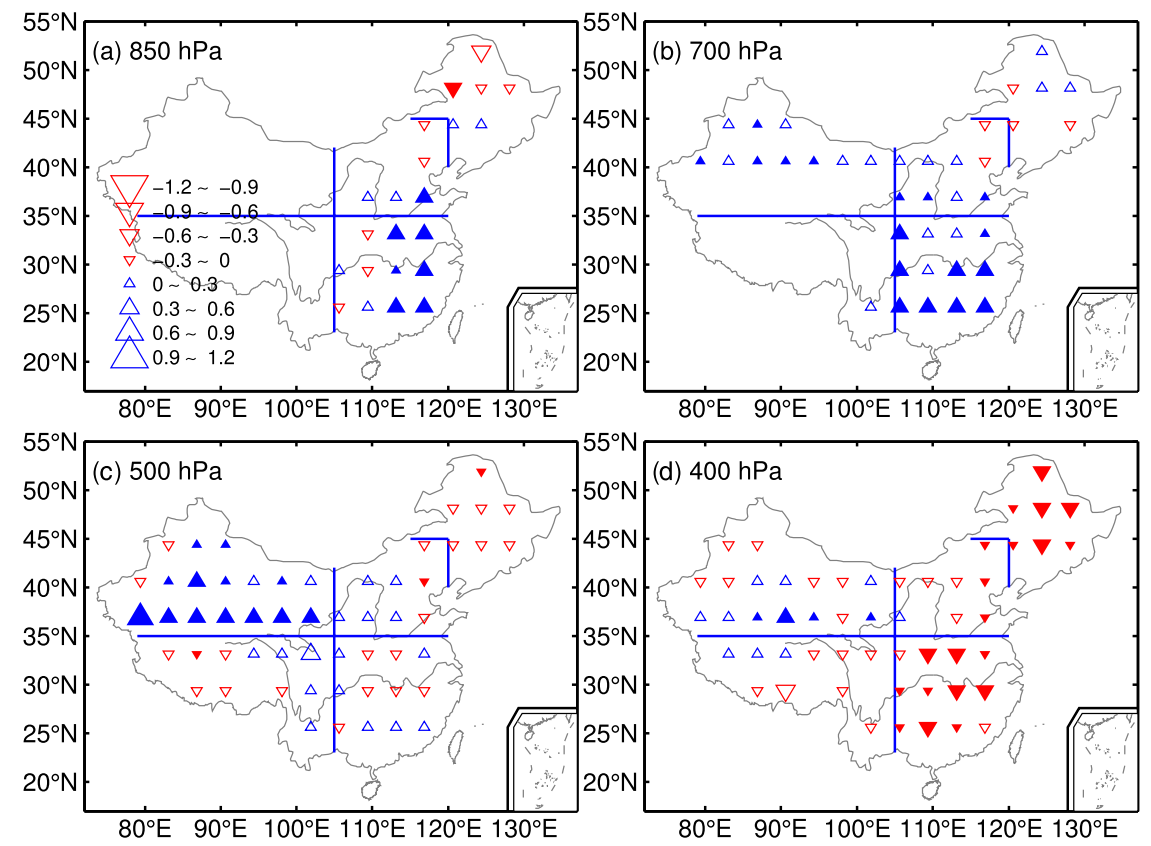

FIG. 5. As in Fig. 4, but derived from the MERRA reanalysis dataset: (a) 850, (b) 700, (c) 500, and (d) $400 \mathrm{hPa}$. Unit is days per summer.

homogenized humidity dataset at that level (Fig. 5). During spring, autumn, and winter, the MERRA reanalysis dataset primarily exhibits decreasing trends over China in the lower and middle troposphere, except for a few indicating increasing trends over northwestern China at $500 \mathrm{hPa}$ in autumn (not shown). The decreasing trends over southeastern China in the lower and middle troposphere are significant at the $95 \%$ confidence level during spring and autumn.

In addition to the MERRA reanalysis dataset, the other reanalysis datasets do not accurately depict the spatial distribution of HRH frequency trends revealed by the homogenized humidity dataset. In all four seasons, increasing trends prevail in the lower and/or middle troposphere over China in the homogenized humidity dataset, particularly in the midtroposphere from spring to autumn. However, these observed widespread increasing trends in the homogenized humidity dataset are not found in most of the reanalysis datasets and are replaced by decreasing trends. Among these reanalysis datasets, the MERRA results are more consistent with the observations. Based on the MERRA results, the increasing $\mathrm{HRH}$ frequency trends in summer support the findings of increasing trends revealed by the homogenized humidity dataset.

\section{b. Vertical profile of HRH frequency trends}

To better describe the vertical changes in the HRH frequency trend in the lower and middle troposphere, vertical profiles of trends in regionally averaged HRH frequency are shown for five regions in China (Fig. 6 and Figs. S1-S3 in the supplemental material). Because of the inhomogeneous distribution of observations over southwestern China in the lower troposphere, the trends in HRH frequency over southwestern China are not calculated for the lower troposphere and are only calculated for the midtroposphere $(500$ and $400 \mathrm{hPa}$; see results in Table 1). As shown in the figure, most of the regions show decreasing trends in the $\mathrm{HRH}$ frequency at the ground level and increasing trends in the lower and/ or middle troposphere during the four seasons. The vertical profile of the HRH frequency trend shows similar features during summer and autumn; increasing trends are found through the lower-to-middle troposphere for each region, except in northern and northwestern China in summer, where increasing trends are only shown in the midtroposphere. During spring, increasing trends occur over northeastern China from 850 to $500 \mathrm{hPa}$, over northern and northwestern China at 700 and $500 \mathrm{hPa}$, over southeastern China at $500 \mathrm{hPa}$, and over southwestern China in the midtroposphere. For winter, increasing trends are only found over each region in the lower troposphere. The vertical profiles of the trend in HRH frequency over China are in accordance with the vertical changes in the trend in mean RH. During summer, significantly increasing trends in mean $\mathrm{RH}$ are observed over China in the midtroposphere. For winter, the increasing trends in mean $\mathrm{RH}$ only occur in 
(a) Northeastern China

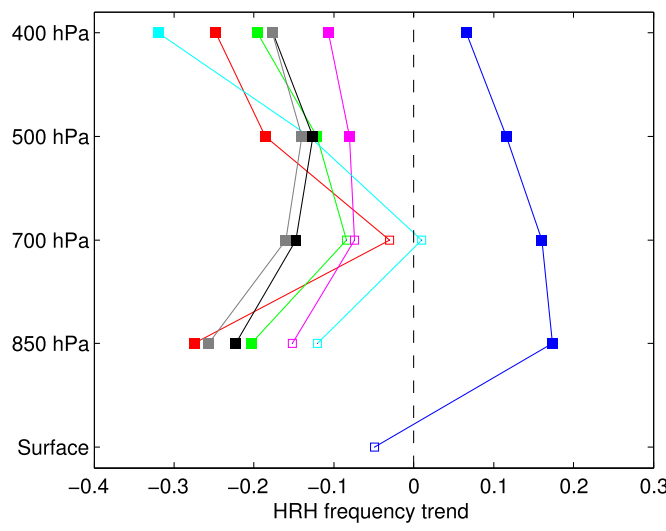

(c) Southeastern China

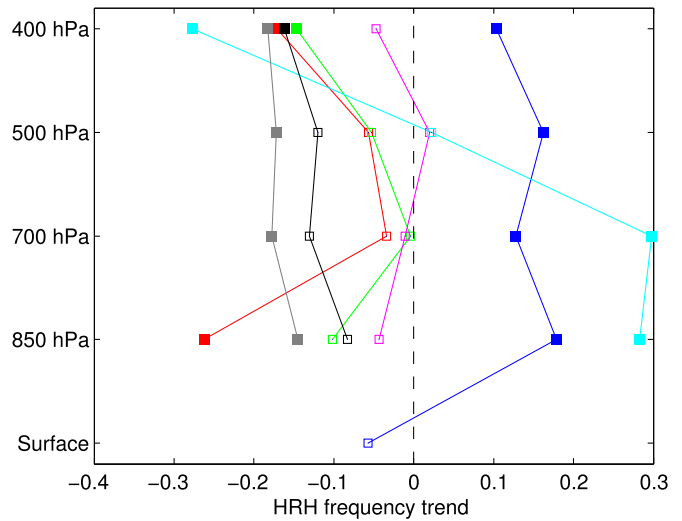

(b) North China

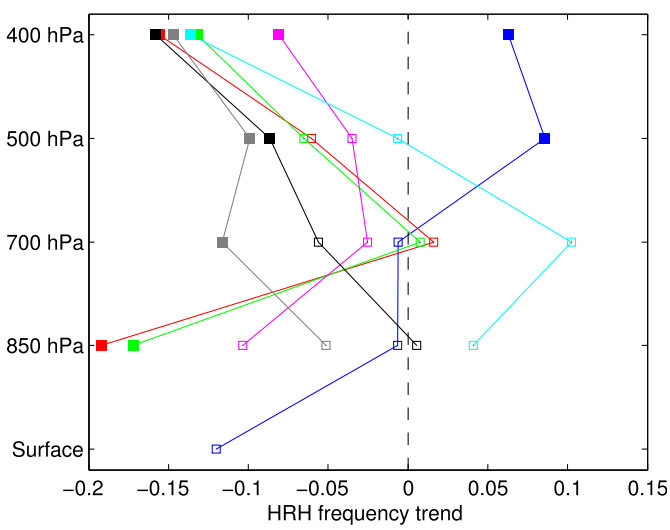

(d) Northwestern China

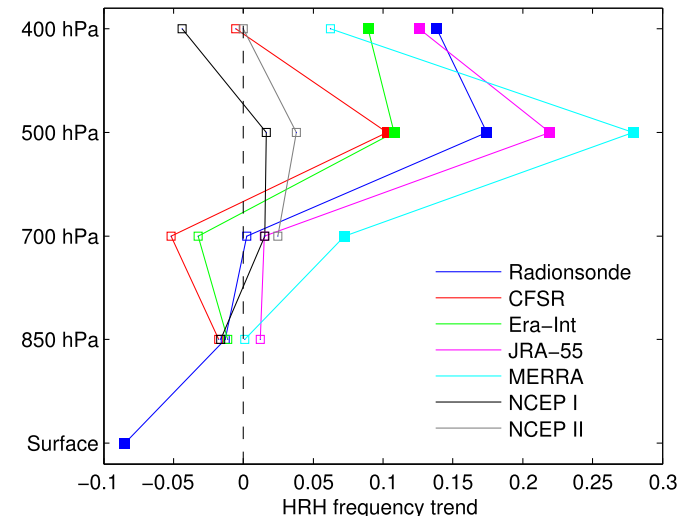

FIG. 6. Vertical profiles of HRH frequency trends in summer computed from radiosonde data and six reanalysis datasets, for the (a) NE, (b) NC, (c) SE, and (d) NW regions (see Fig. 1a for regions). Filled markers are significant at the $95 \%$ confidence level. Unit is days per summer. Results for southwestern China are not shown because only values at 500 and $400 \mathrm{hPa}$ are observed in both types of data. Please see Table 1 for trends in $\mathrm{HRH}$ frequency over southwestern China.

the lower troposphere ( $850 \mathrm{hPa}$ ) (Xie et al. 2011). Zhao et al. (2012) analyzed the nationwide-averaged RH from 1970 to 2008 . The trends for RH are positive mostly in summer and above $850 \mathrm{hPa}$ and negative in the lower troposphere; the RH trends are decreasing in spring in the lower troposphere.

The vertical profiles of the HRH frequency trend derived from the six reanalysis datasets were compared to that from the homogenized humidity dataset. Because of nonexistence of RH data at the ground level in some of the reanalysis datasets, only the HRH frequency trends from 850 to $400 \mathrm{hPa}$ are shown in the reanalysis datasets. First, the vertical profiles of the HRH frequency trend derived from the six reanalysis datasets were compared (Fig. 6). The vertical trend profiles over most of the regions are similar among the six reanalysis datasets during spring, summer, and autumn and are characterized by low values at $850 \mathrm{hPa}$, high values at 700 and $500 \mathrm{hPa}$, and low values at $400 \mathrm{hPa}$. For example, in the CFSR result, the trend is $-0.19(-0.26)$ days per spring at $850 \mathrm{hPa}$ for northern China (southeastern China); this becomes $-0.06(-0.06)$ days per spring at $500 \mathrm{hPa}$ and then decreases to $-0.16(-0.17)$ days per spring (Table 1 and Fig. S1). Similarly, in the MERRA result, the trend is $0.0(-0.03)$ days per autumn at $850 \mathrm{hPa}$ over northwestern China (northern China) during autumn; it increases to $0.11(-0.11)$ days per autumn at $700 \mathrm{hPa}$ and then decreases (Fig. S2). However, the vertical profiles of the trend in HRH frequency exhibit different patterns for different regions in winter. The vertical profile of HRH frequency trend shows that the trend increases (decreases) from 850 to $500 \mathrm{hPa}$ over northeastern and northwestern China (over southeastern China) (Fig. S3).

Furthermore, the vertical profiles of the HRH frequency trend derived from multiple reanalysis datasets are compared to that from the homogenized humidity dataset. The HRH frequency trends derived from the 
TABLE 1. Trends in the time series of HRH frequency over China during summer. Numbers in boldface are significant at the $95 \%$ confidence level.

\begin{tabular}{|c|c|c|c|c|c|}
\hline & \multicolumn{5}{|c|}{ Region } \\
\hline & $\mathrm{NE}$ & $\mathrm{NC}$ & SE & SW & NW \\
\hline \multicolumn{6}{|c|}{ Radiosonde data } \\
\hline $400 \mathrm{hPa}$ & 0.07 & 0.06 & 0.1 & 0.3 & 0.14 \\
\hline $500 \mathrm{hPa}$ & 0.12 & 0.09 & 0.16 & 0.34 & 0.17 \\
\hline $700 \mathrm{hPa}$ & 0.16 & -0.01 & 0.13 & - & 0 \\
\hline $850 \mathrm{hPa}$ & 0.17 & -0.01 & 0.18 & - & -0.01 \\
\hline \multicolumn{6}{|l|}{ MERRA } \\
\hline $400 \mathrm{hPa}$ & -0.32 & -0.14 & -0.28 & -0.08 & 0.06 \\
\hline $500 \mathrm{hPa}$ & -0.13 & -0.01 & 0.02 & 0.04 & 0.28 \\
\hline $700 \mathrm{hPa}$ & 0.01 & 0.1 & 0.3 & - & 0.07 \\
\hline $850 \mathrm{hPa}$ & -0.12 & 0.04 & 0.28 & - & 0 \\
\hline \multicolumn{6}{|l|}{ CFSR } \\
\hline $400 \mathrm{hPa}$ & -0.25 & -0.16 & -0.17 & 0.06 & -0.01 \\
\hline $500 \mathrm{hPa}$ & -0.19 & -0.06 & -0.06 & 0.23 & 0.1 \\
\hline $700 \mathrm{hPa}$ & -0.03 & 0.02 & -0.03 & - & -0.05 \\
\hline $850 \mathrm{hPa}$ & -0.27 & -0.19 & -0.26 & - & -0.02 \\
\hline \multicolumn{6}{|c|}{ ERA-Interim } \\
\hline $400 \mathrm{hPa}$ & -0.2 & -0.13 & -0.15 & -0.02 & 0.09 \\
\hline $500 \mathrm{hPa}$ & -0.12 & -0.07 & -0.05 & 0.18 & 0.11 \\
\hline $700 \mathrm{hPa}$ & -0.08 & 0.01 & 0 & - & -0.03 \\
\hline $850 \mathrm{hPa}$ & -0.2 & -0.17 & -0.1 & - & -0.01 \\
\hline \multicolumn{6}{|l|}{ JRA-55 } \\
\hline $400 \mathrm{hPa}$ & -0.11 & -0.08 & -0.05 & 0.05 & 0.13 \\
\hline $500 \mathrm{hPa}$ & -0.08 & -0.04 & 0.02 & 0.16 & 0.22 \\
\hline $700 \mathrm{hPa}$ & -0.07 & -0.03 & -0.01 & - & 0.02 \\
\hline $850 \mathrm{hPa}$ & -0.15 & -0.1 & -0.04 & - & 0.01 \\
\hline \multicolumn{6}{|l|}{ NCEP-1 } \\
\hline $400 \mathrm{hPa}$ & -0.18 & -0.16 & -0.16 & 0.01 & -0.04 \\
\hline $500 \mathrm{hPa}$ & -0.13 & -0.09 & -0.12 & -0.07 & 0.02 \\
\hline $700 \mathrm{hPa}$ & -0.15 & -0.06 & -0.13 & - & 0.02 \\
\hline $850 \mathrm{hPa}$ & -0.22 & 0.01 & -0.08 & - & -0.02 \\
\hline \multicolumn{6}{|l|}{ NCEP-2 } \\
\hline $400 \mathrm{hPa}$ & -0.18 & -0.15 & -0.18 & 0.01 & 0 \\
\hline $500 \mathrm{hPa}$ & -0.14 & -0.1 & -0.17 & -0.12 & 0.04 \\
\hline $700 \mathrm{hPa}$ & -0.16 & -0.12 & -0.18 & - & 0.02 \\
\hline $850 \mathrm{hPa}$ & -0.26 & -0.05 & -0.15 & - & - \\
\hline
\end{tabular}

homogenized humidity dataset and multiple reanalysis datasets are different in their values; however, the shapes of vertical distribution of HRH frequency trend are similar during spring, summer and autumn between two data types, except for northwestern China (north China) in spring (summer). In most cases, the trends increase from 850 to 700 or $500 \mathrm{hPa}$ and then decrease at $400 \mathrm{hPa}$ in both dataset types during spring, summer, and autumn. Meanwhile, the reanalysis datasets and the homogenized humidity dataset present high values of trends at 850 and $700 \mathrm{hPa}$ and low values of trends at 500 and $400 \mathrm{hPa}$ over northeastern China (southeastern China) in spring (autumn). During winter, however, the vertical profiles of $\mathrm{HRH}$ frequency trend derived from multiple reanalysis datasets are not consistent with that from the homogenized humidity dataset over China. Except for southeastern China, the HRH frequency trends increase from 850 to $400 \mathrm{hPa}$ over China in most of the reanalysis datasets. Yet in the homogenized humidity dataset, the vertical profile of $\mathrm{HRH}$ frequency trend presents positive trends at 850 and $700 \mathrm{hPa}$ and nearly zero trends at $500-400 \mathrm{hPa}$. For southeastern China in winter, both dataset types exhibit relatively large values of trends at 850 and $700 \mathrm{hPa}$ and low values of trends in the midtroposphere.

In conclusion, most of the reanalysis datasets, including the MERRA dataset, cannot fully reproduce the spatial and vertical variations in HRH frequency trends observed in the homogenized humidity dataset. This inconsistency in the HRH frequency trends between the reanalysis datasets and the homogenized humidity dataset may be related to the fact that the reanalysis datasets assimilated radiosonde humidity data without any homogenization. The unadjusted radiosonde humidity data contained discontinuities in DPD records, which resulted from a change in radiosonde type or observational practice and often made reanalysis datasets unsuitable for humidity trend analyses (Trenberth et al. 2005; Qian et al. 2006; Dai et al. 2011). To display the discontinuities between the homogenized humidity dataset and the reanalysis datasets, the time series of summer HRH frequency from the two data types were compared as an example (Fig. 7). For clarity, the time series of HRH frequency at 850 and $500 \mathrm{hPa}$ are shown to represent those in the lower and middle troposphere, respectively. Since there are few stations or grid points over southwestern China and northwestern China at $850 \mathrm{hPa}$, only time series at $500 \mathrm{hPa}$ are exhibited for these regions. The reanalysis datasets show good performance to reproduce the time series of $\mathrm{HRH}$ frequency derived from the homogenized humidity dataset on an interannual time scale (long-term trends excluded from the data). On the interannual time scale, most of the Spearman's correlation coefficients of HRH frequency time series are above 0.5 between the two data types during 1979-2012, which are significant at the 95\% confidence level. On a long-term time scale, however, there are poor agreements in the time series of HRH frequency between the reanalysis datasets and the homogenized humidity data after the mid-1990s, resulting in opposite trends in the HRH frequency time series during 1979-2012 between the two data types. For example, at the 500-hPa level and over southeastern China, all of the reanalysis datasets show a high Spearman's correlation coefficient above 0.75 with HRH frequency time series in the homogenized humidity dataset during 1979-95. However, when the 

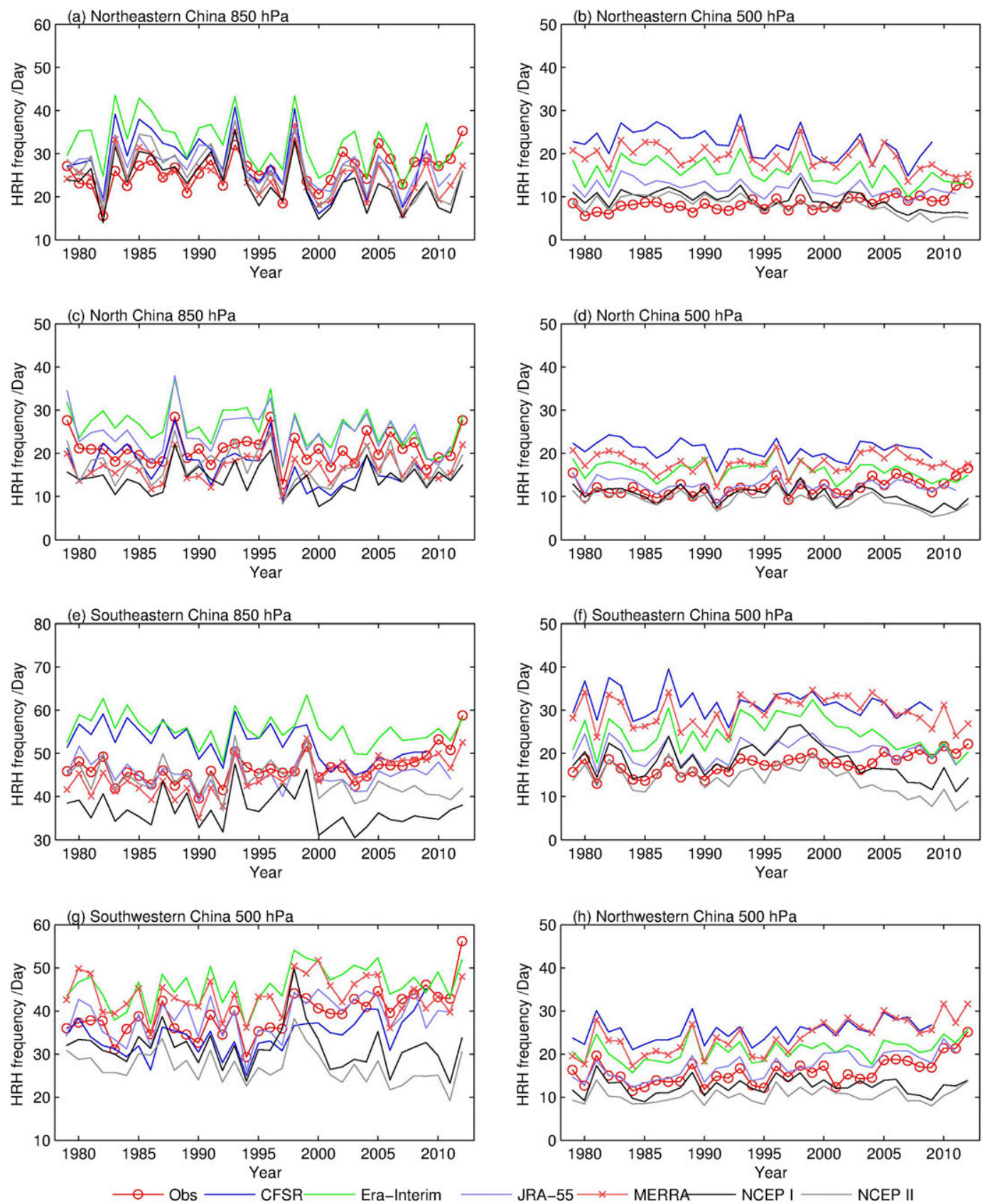

FIG. 7. Time series of HRH frequency in the low-to-middle troposphere over China during summer for (a),(b) northeastern, (c),(d) northern, and (e),(f) southeastern China regions at the 850- and 500-hPa levels, respectively. For topographic reasons, only the time series of $\mathrm{HRH}$ frequency at $500 \mathrm{hPa}$ are shown for $(\mathrm{g})$ southwestern China and $(\mathrm{h})$ northwestern China.

time series of HRH frequency after the mid-1990s is involved in correlation study, the correlations of HRH frequency time series during 1979-2012 between the reanalysis datasets and the homogenized humidity dataset become weak and only the CFSR, JRA-55, and MERRA show a significant correlation with a correlation coefficient of about 0.5 , significant at the $95 \%$ confidence level. Thus, we have higher confidence in the ability of these reanalysis datasets to accurately simulate the interannual changes in HRH frequency. The poor agreements in the long-term trend of $\mathrm{HRH}$ frequency after the mid-1990s between the two data types was supported by Dessler and Davis (2010), who showed that data inhomogeneities introduce long-term 
(a) Total cloud amount

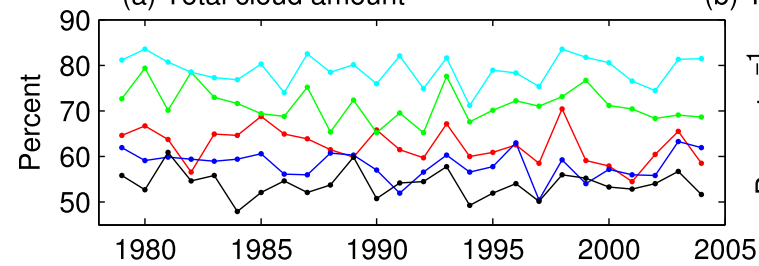

(c) Low-mid cloud amount

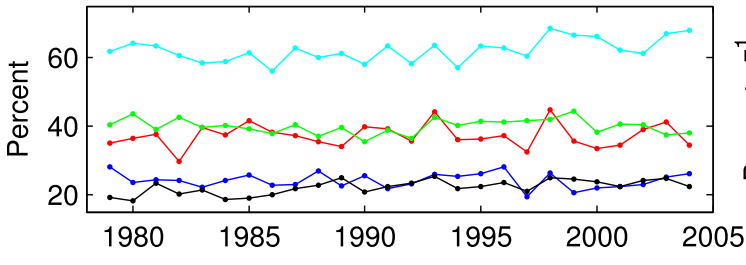

SE (b) Trend in total cloud amount

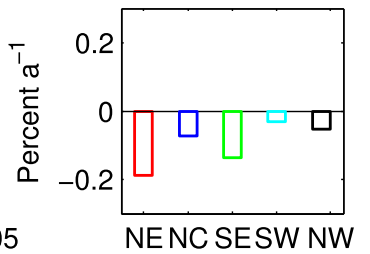

(d) Trend in low-mid cloud amount

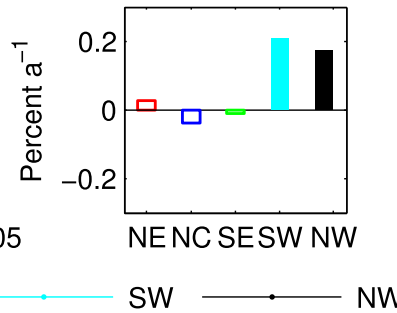

FIG. 8. Cloud amount time series (\%) and its trend in summer ( $\%$ summer $\left.^{-1}\right)$ for (a),(b) total cloud amount and (c),(d) low-to-middle cloud amount, for NE, NC, SE, SW, and NW regions. Trends at the $95 \%$ confidence level are filled bars.

trends in the reanalysis datasets but with less of an effect on short-term trends. In addition, by referencing the correlation coefficients of $\mathrm{HRH}$ frequency time series between the reanalysis datasets and the homogenized humidity dataset, NCEP-1 and NCEP-2 may have a relatively weak correlation with the homogenized humidity dataset as compared to the other reanalysis datasets. This is because the newest reanalysis datasets such as MERRA and ERA-Interim used variational bias correction algorithms (Dee and Uppala 2009) to address well-documented contamination issues in climate signals (Dee 2005; Bengtsson et al. 2007).

\section{Trends in cloud amount in the troposphere}

\section{a. Trends in cloud amount derived from observations}

HRH in the troposphere, in particular in the lower and middle troposphere, is tightly associated with the occurrence of cloud layers. Thus, variations in $\mathrm{HRH}$ frequency may be due to changes in cloud amount. Here, cloud amount time series and their trends are discussed to support the increasing trends in HRH frequencies in the lower and middle troposphere revealed by the homogenized humidity dataset. Climatologically, the total cloud amount is higher over southern China compared with northern China, with values of $60 \%-$ $80 \%(70 \%-90 \%)$ and $40 \%-60 \%(50 \%-70 \%)$ over southern and northern China in spring (summer), respectively, and of $60 \%$ (40\%) over southern (northern) China in autumn. In winter, the total cloud amount over southeastern China is $60 \%-80 \%$, which is higher than that found over the other regions by $20 \%-50 \%$. Regarding the low-to-middle cloud amount, its climatological value is $30 \%-60 \%$ (less than $20 \%$ ) over southern (northern) China in spring, autumn, and winter. Meanwhile, the summer low-to-middle cloud amount is high over southeastern China ( $\sim 60 \%)$ and low over the remaining regions $(15 \%-40 \%)$.

Based on the cloud amount time series, trends in the regional cloud amounts were calculated (Fig. 8 for summer; figures not shown for other seasons). The total cloud amounts exhibit negative trends over each region in China in spring and summer, although these trends are not significant at the $95 \%$ confidence level. In autumn and winter, the total cloud amount trends are approximately zero, except for some negative values over southeastern China in autumn and over southwestern China in winter. The negative total cloud amount trends over China are supported by the International Satellite Cloud Climatology Project (ISCCP), the ECMWF reanalysis datasets, and the ground station dataset, which show a slight decreasing trend in total cloudiness over China (e.g., $\mathrm{Xu}$ 2012; Zong et al. 2013). In contrast to the total cloud amount, positive low-to-middle cloud amount trends are observed over some parts of China in all four seasons. For example, positive low-to-middle cloud amount trends over northwestern China during all four seasons and over southwestern China in summer can be observed; these trends are significant at the $95 \%$ confidence level.

In addition, the spatial distribution of the total cloud amount and low-to-middle cloud amount trends over China were also analyzed (Fig. 9 for summer; figures not shown for other seasons). The results show that there are significant negative total cloud amount trends over 

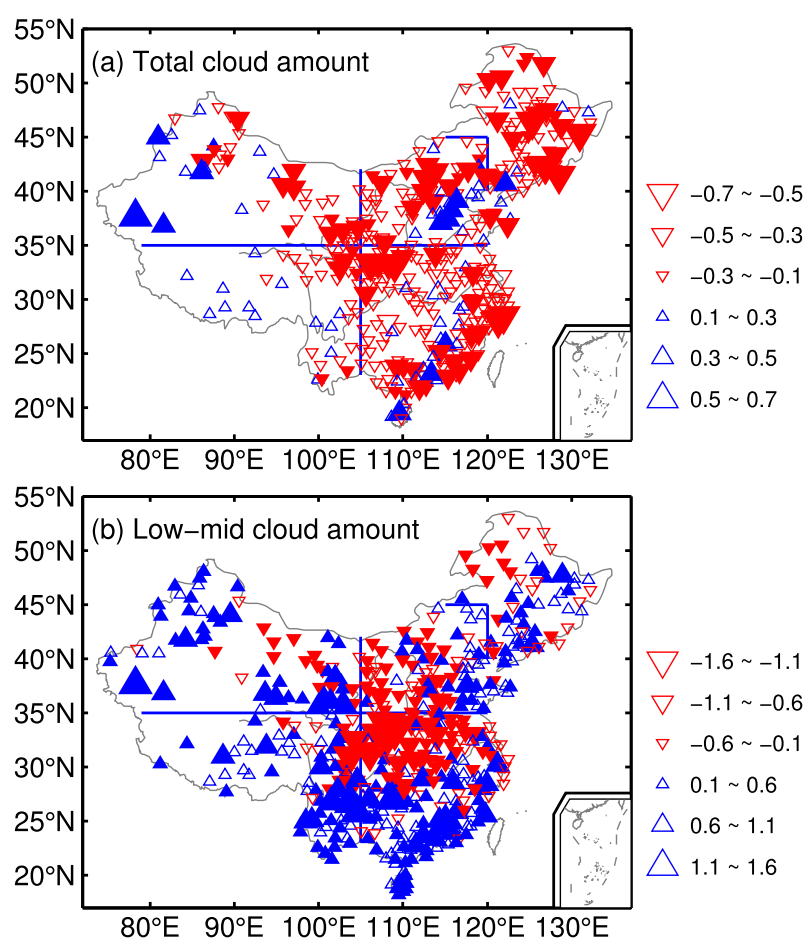

FIG. 9. Spatial distributions of cloud amount trend in summer (\% summer ${ }^{-1}$ ) over China: (a) total and (b) low-to-middle cloud amount. Filled markers are significant at the $95 \%$ confidence level.

China in spring and summer, whereas negative trends are found in autumn (winter) over southeastern China (southwestern China), with positive trends found primarily over northern China in autumn and winter. Regarding the low-to-middle cloud amounts, negative trends are found for all four seasons in central China, but not in southeastern and northern China in spring; the negative trends are accompanied by surrounding positive trends during all four seasons. The distribution of decreasing trends in central China surrounded by increasing trends was also revealed in a previous study using ground station datasets in China ( $\mathrm{Xu}$ 2012).

Long-term changes in the low-to-middle cloud amounts provide a possible explanation for the increasing HRH frequencies in parts of China during recent decades. The increasing low-to-middle cloud amount trends in spring to autumn over northeastern, southwestern, and northwestern China are consistent with the positive HRH frequency trends. Moreover, the negative HRH frequency trends over southeastern China (north-central China) in the lower troposphere in spring (summer) are explained by the negative low-tomiddle cloud amount trends in this region. However, on an interannual time scale, there are low correlations between HRH frequency and low-to-middle cloud amount over China except for northwestern China, indicating a poor explanation of the low-to-middle cloud amount for the variations in HRH frequency on the interannual time scale. It seems that another mechanism(s) (other than low-to-middle cloud amount changes) must be considered to better understand the observed increase in HRH frequencies over central China in the midtroposphere.

\section{b. Trends in cloud amount derived from reanalysis datasets}

Trends in the cloud amount derived from six reanalysis datasets were calculated and then compared to that from observations. Some reanalysis datasets involve total cloud amount (ERA-Interim, JRA-55, NCEP-1, and NCEP-2) and others only provide low-cloud and medium-cloud amounts (CFSR, ERA-Interim, JRA-55, and MERRA). Trends in the total cloud amount revealed by the ERA-Interim, JRA-55, and NCEP-2 datasets show similar spatial patterns in summer, autumn, and winter (not shown). Increasing trends are observed over western China during summer and autumn and over northern China during winter; other regions are overwhelmed by decreasing trends during these seasons. For a low cloud amount, the reanalysis datasets show decreasing trends over China. However, medium cloud amounts are featured by increasing trends over western China during the four seasons in the reanalysis datasets, especially over northwestern China. In conclusion, the trends in a medium cloud amount observed in the reanalysis datasets are consistent with the increasing trends in the low-to-middle cloud amount over northwestern China revealed by observations.

Here, the result of the MERRA dataset is shown as an example to describe the changes in cloud amount revealed by the reanalysis datasets. In the MERRA reanalysis dataset (Fig. 10 for summer; figures not shown for other seasons), three types of clouds (large-scale clouds, anvil clouds, and convective clouds) were observed, and the cloud fractions of these cloud types were measured at every level from the surface to the upper troposphere. To compare with the low-to-middle cloud amount in the observations, the average cloud fractions were calculated between 1000 and $850 \mathrm{hPa}(825$ and $500 \mathrm{hPa}$ ) for the three cloud types, which could represent a low (medium) cloud amount in the troposphere.

In general, there are no results for convective clouds because of few records of this cloud type. However, anvil clouds and large-scale clouds show evident trends in their cloud amount over China. The spatial distribution of trends in low-cloud and medium-cloud amount are similar for anvil clouds and large-scale clouds, although there are more grid points shown in the results of 

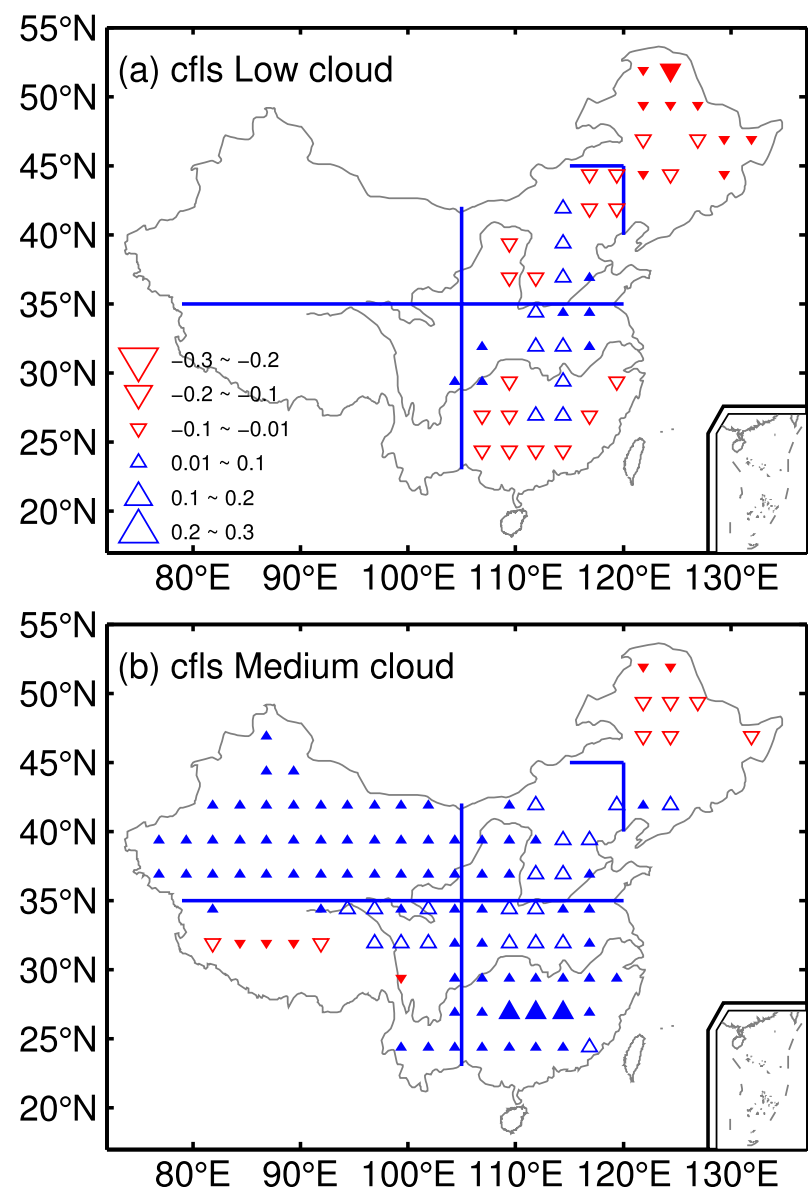

FIG. 10. Spatial distributions of cloud fraction trend derived from the MERRA reanalysis dataset in summer $\left(\%\right.$ summer $\left.^{-1}\right)$ over China, for large-scale (a) low cloud and (b) medium cloud. Filled markers are significant at the $95 \%$ confidence level.

large-scale clouds than of anvil clouds. The spatial distributions of trends in low-cloud and medium-cloud amounts for large-scale clouds are similar during summer and autumn; the low-cloud (medium-cloud) amount decreases (increases) over eastern China (over all of China) for large-scale clouds. In spring and winter, decreasing trends prevail over China for a medium cloud amount. In conclusion, the increasing trends in mediumcloud amounts for large-scale clouds and anvil clouds support the increasing trends in the low-to-middle cloud amount observed in the cloud observations during summer and autumn.

\section{Discussion}

\section{a. Changes in the frequency distribution of $R H$}

In this study, a $\mathrm{RH}$ of at least $80 \%$ was addressed and changes in the frequency of high $\mathrm{RH}(80 \%-100 \%)$ were analyzed. In addition to a $\mathrm{RH}$ of $80 \%-100 \%$, it is interesting to examine the variations in the frequency of all $\mathrm{RH}$ values, including low $\mathrm{RH}$ and relatively high $\mathrm{RH}$, and whether the frequencies of all $\mathrm{RH}$ values, as well those greater than $80 \%$, show increasing trends in the lower and middle troposphere. Here, the frequency distributions of $\mathrm{RH}$ were analyzed for each level from the surface to the midtroposphere during the four seasons. In the homogenized humidity dataset, the frequency distributions of RH vary greatly among the levels from the surface to the midtroposphere and vary among the seasons. It is difficult to depict the frequency distribution of RH using a specific probability density function and then to estimate the changes in the $\mathrm{RH}$ frequency by merit of the specific probability density function. For example, the RH frequency at the ground level shows a quasi-normal distribution in spring, but it is characterized by low frequency for low $\mathrm{RH}$ and high frequency for high RH during other seasons, with a peak at a $\mathrm{RH}$ of $70 \%-90 \%$. In the midtroposphere, the $\mathrm{RH}$ frequencies during the four seasons have a high value at a $\mathrm{RH}$ less than $30 \%$ and a low value at a $\mathrm{RH}$ within $30 \%$ and $90 \%$. To reveal the variations in the frequency of all $\mathrm{RH}$ values, the analyzed period is separated into two subperiods (1979-95 and 19962012), and changes in the RH frequency in different $\mathrm{RH}$ intervals are compared between the two subperiods.

Results show that the frequencies of RH within $80 \%-90 \%$ significantly increase over China in the mid (lower) troposphere in spring, summer, and autumn (winter), while the frequencies of $\mathrm{RH}$ in the other intervals weakly decrease (Fig. 11 for summer; figures not shown for other seasons). For example, during summer and autumn, the RH frequency increases by $1 \%-6 \%$ in the interval of $80 \%-90 \%$ in the midtroposphere, followed by a decreasing $\mathrm{RH}$ frequency in the other intervals. In the homogenized humidity dataset, the increases in RH frequency within $80 \%-90 \%$ contribute more to the upward trend of HRH frequency in the mid (lower) troposphere in spring, summer, and autumn (winter). Mechanisms resulting in the upward frequency of RH within $80 \%-90 \%$ in the midtroposphere need further studies, which are beyond the scope of this paper.

Similarly, the RH frequencies derived from the reanalysis datasets were compared between the two subperiods. Most of the reanalysis datasets show decreasing frequencies of $\mathrm{RH}$ in the intervals of $50 \%-100 \%$ in the midtroposphere, which contrast those in the homogenized humidity dataset. The RH frequencies calculated from the reanalysis datasets increase in the intervals of $\mathrm{RH}$ less than $50 \%$. Here, results from the MERRA 
(a) Surface

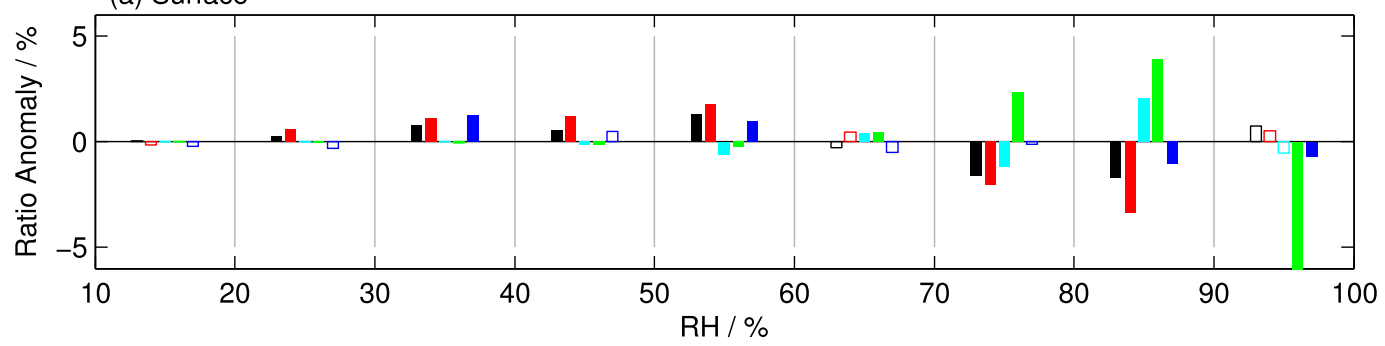

(b) $850 \mathrm{hPa}$

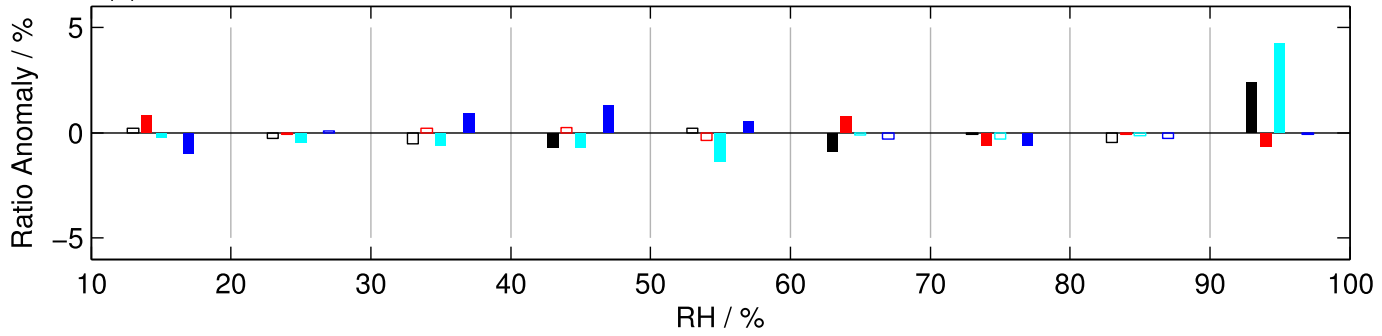

(c) $700 \mathrm{hPa}$

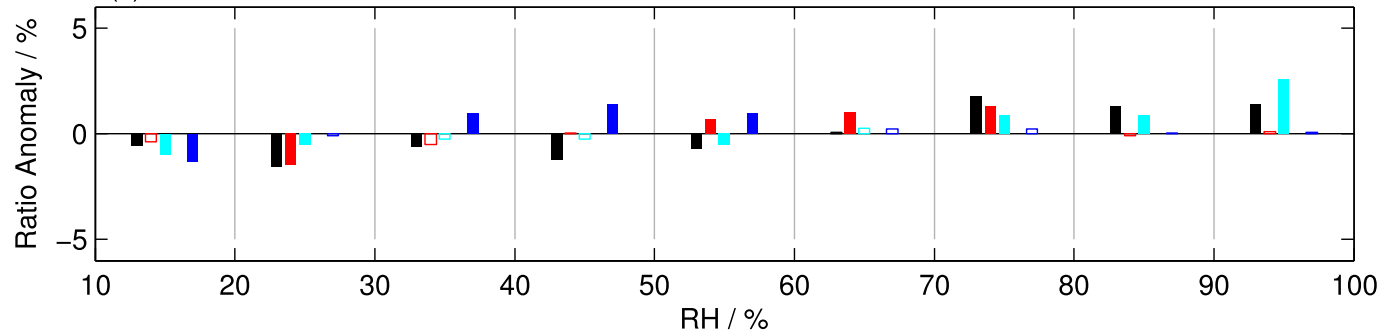

(d) $500 \mathrm{hPa}$

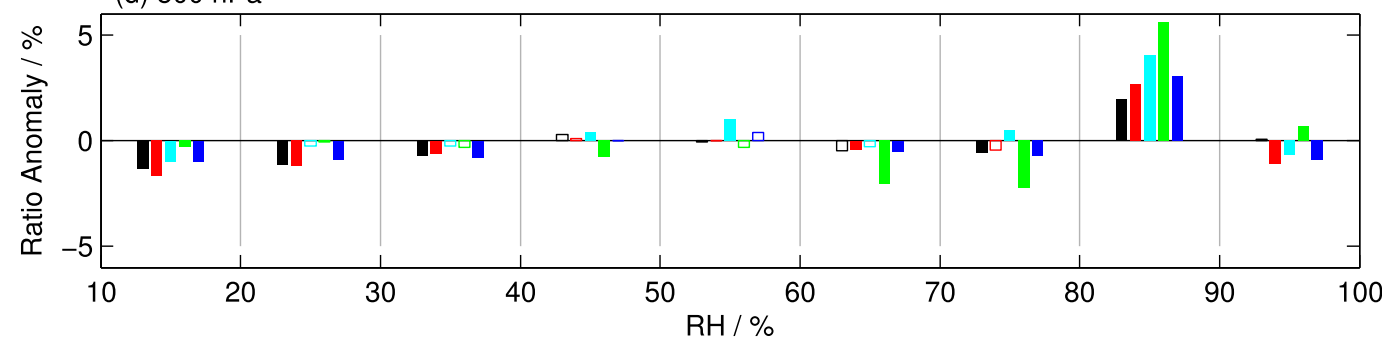

(e) $400 \mathrm{hPa}$

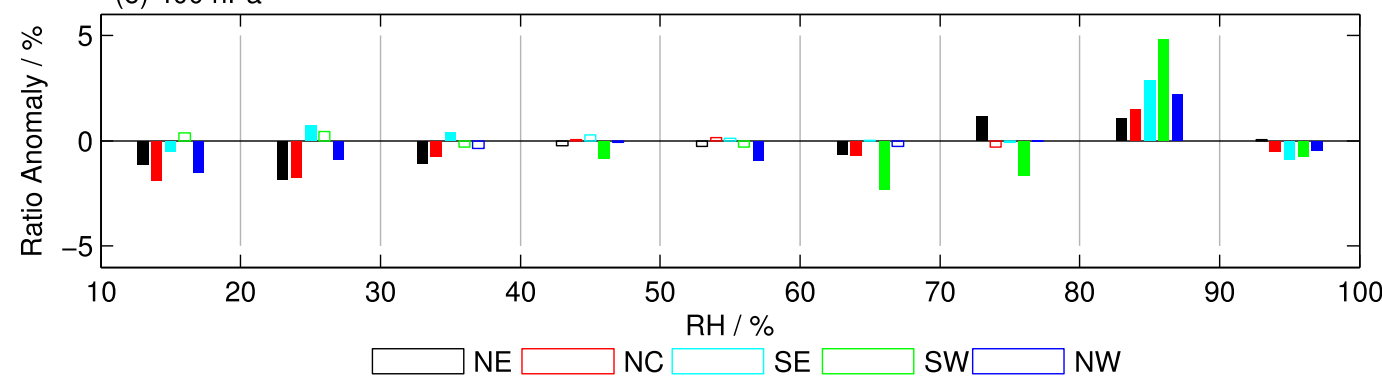

FIG. 11. Difference in RH frequency for different RH intervals in summer (1996-2012 minus 1979-95), which is derived from the homogenized humidity dataset and for NE, NC, SE, SW, and NW regions. Filled bars are significant at the $95 \%$ confidence level. Unit is percent.

reanalysis dataset are shown as an example (Fig. 12 for summer; figures not shown for other seasons). During spring, autumn, and winter, the $\mathrm{RH}$ frequencies decrease in the interval of $50 \%-100 \%$ by approximately
$2 \%$, while the frequencies for $\mathrm{RH}$ values less than $50 \%$ increase. However, during summer, the frequency of $80 \%-100 \%$ RH increases over northern, southeastern, and northwestern China at $700 \mathrm{hPa}$, while those for the 
(a) $850 \mathrm{hPa}$

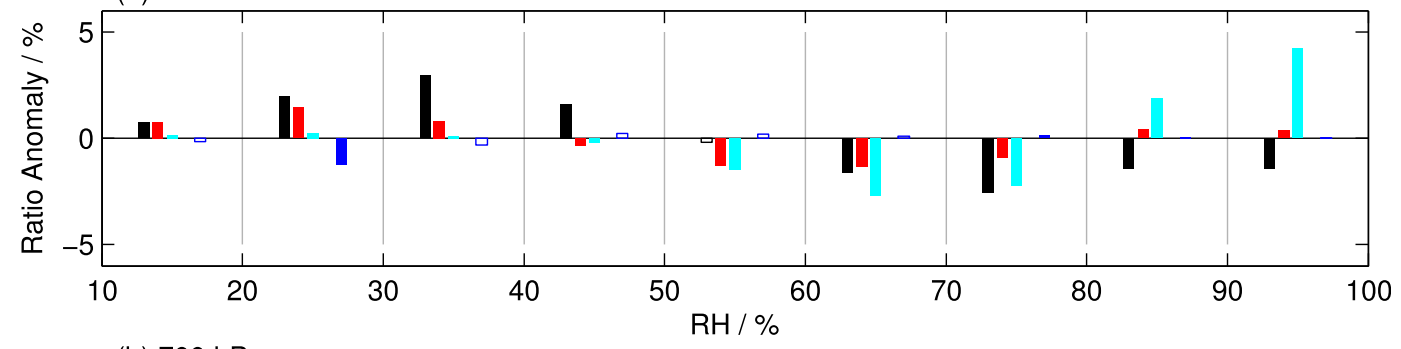

(b) $700 \mathrm{hPa}$

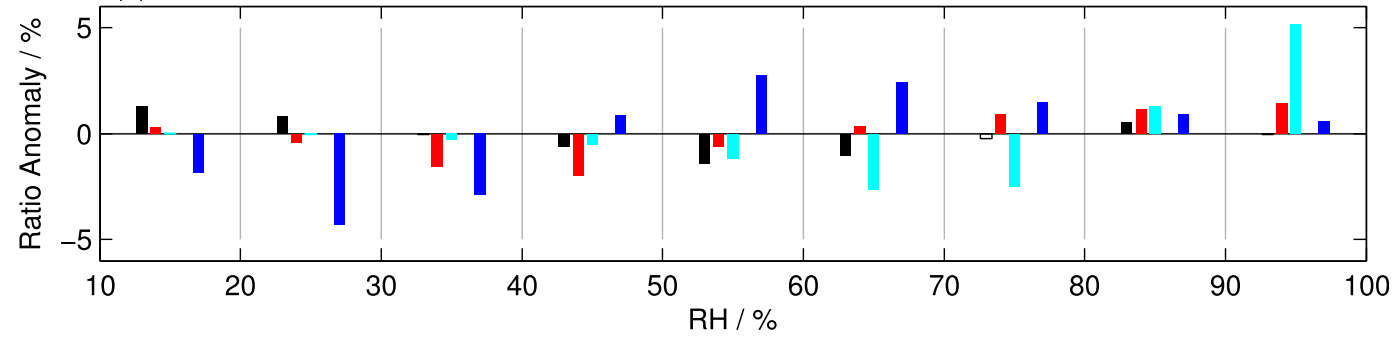

(c) $500 \mathrm{hPa}$

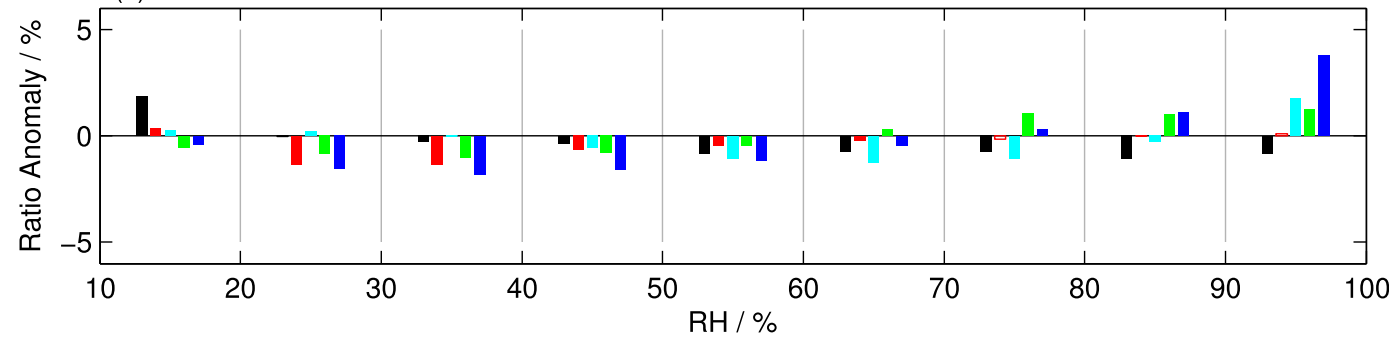

(d) $400 \mathrm{hPa}$

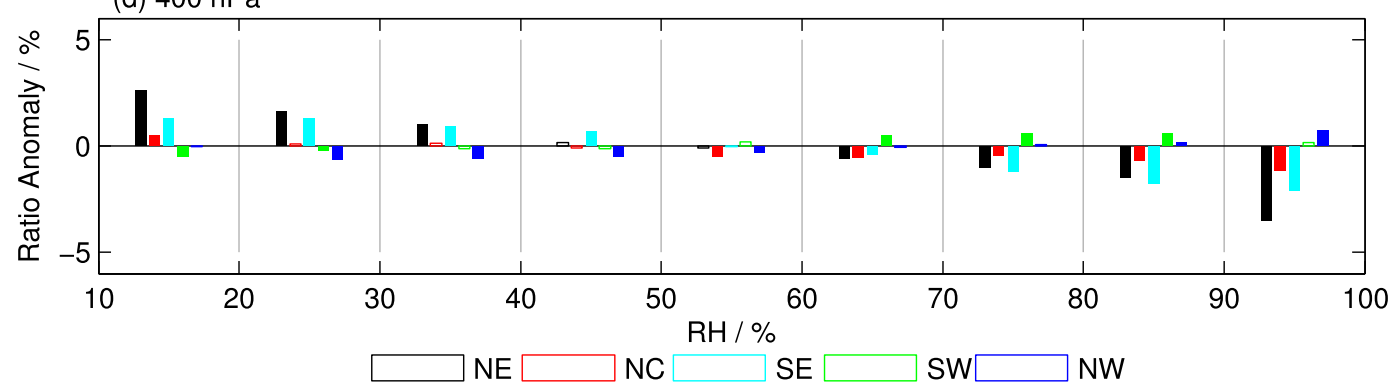

FIG. 12. As in Fig. 11, but derived from the MERRA reanalysis dataset: (a) 850, (b) 700, (c) 500, and (d) $400 \mathrm{hPa}$. Unit is percent.

interval of $90 \%-100 \%$ also significantly increase in the midtroposphere $(500 \mathrm{hPa})$.

\section{b. Effect of long-term trends on rainy days}

Rainy days are generally associated with HRH in the troposphere, especially in the lower and middle troposphere. As a result, long-term changes on rainy days will likely result in variations in HRH frequencies in the lower and middle troposphere. Some authors have indicated a significant decreasing trend in light rainfall frequency over eastern Asia with a high spatial coherency over the period 1973-2009, although moderate and heavy rain events have increased (e.g., Endo et al. 2005; Qian et al.
2010). To elucidate the increasing trends in HRH frequencies in the lower and middle troposphere revealed by the homogenized humidity dataset, we recalculated the HRH frequency trends using nonrain observations (i.e., the daily $\mathrm{RH}$ on a rainy day was removed before recalculating the HRH frequency with the remaining data). After data quality control, only a few stations were retained; hence, only the results at 850,700 , and $500 \mathrm{hPa}$ were analyzed. The spatial distributions of trends derived using the nonrain data not only resemble those derived from the data including rainy days at these levels but also show higher percentages of stations exhibiting positive trends compared with the original data (not shown). The 
(a) Spring

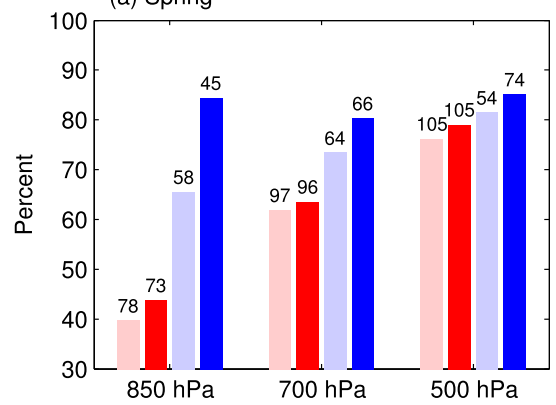

(c) Autumn

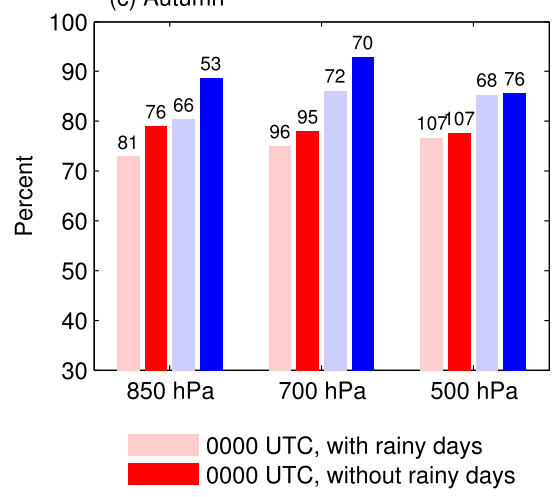

(b) Summer

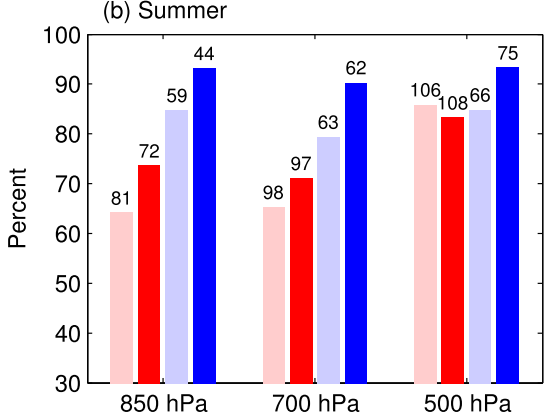

(d) Winter

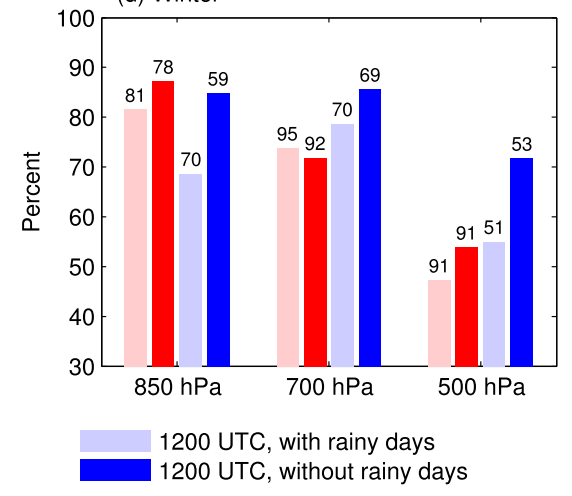

FIG. 13. Percentage of stations of positive HRH frequency trend in (a) spring, (b) summer, (c) autumn, and (d) winter. Dark (light) color exhibits trend calculated from data without (with) rainy days. Numbers over bars are the number of stations in analysis.

majority of stations in the lower and middle troposphere exhibit positive trends over China during all four seasons, except those in winter at $500 \mathrm{hPa}$, where half of the stations are characterized by positive trends. For example, in spring, the negative trends over southeastern China in the lower troposphere revealed in the original data are replaced by positive trends when rainy days are excluded.

For clarification, the percentages of stations exhibiting positive trends in the data with and without rainy days were compared (Fig. 13). Although fewer stations are available when nonrain data were analyzed, there is an increase in the percentage of stations exhibiting positive trends in spring to autumn, particularly at 850 and $700 \mathrm{hPa}$, compared to those from the data including rainy days. In addition, the percentages of stations exhibiting positive trends at 0000 and 1200 UTC were compared. The percentage of stations exhibiting positive trends at 1200 UTC is higher than at 0000 UTC in all four seasons. In summary, the results from the data excluding rainy days further support the finding that the HRH frequencies have increased in the lower-to-middle troposphere during recent decades in all four seasons.

\section{c. Effect of discontinuities in radiosonde humidity data}

Although large discontinuities existing in the occurrence frequency and histograms of daily dewpoint depression
(DPD) were removed from the homogenized humidity dataset, it is suspected that our finding (i.e., the increasing trends in HRH frequencies in the lower-to-middle troposphere derived from this dataset) is spurious and is caused by discontinuities in the daily DPD time series. Here, we discuss the influence of general discontinuities in the humidity dataset on the HRH frequency trends, including a review of the accuracy under cold conditions and response time. First, regarding the accuracy under cold conditions, Zhai and Eskridge (1997) and McCarthy et al. (2009) described a sampling problem that is related to measurements at cold temperatures (ambient air temperature $<-40^{\circ} \mathrm{C}$ ). Most early radiosonde hygrometers were considered unreliable under such cold conditions (Remsberg et al. 2000), and it was standard practice for U.S. stations to report humidity measurements as missing when the temperature was below $-40^{\circ} \mathrm{C}$. Dai et al. (2011) revealed that there were fewer DPD reports in early observations, even for conditions with temperatures from $-30^{\circ}$ to $-40^{\circ} \mathrm{C}$. Clearly, these earlier missing humidity records would induce a bias toward wetter conditions relative to more recent observations, which opposes the wetting trend observed in this study during recent decades.

In addition to the sampling problem under cold conditions that can cause discontinuities in the daily DPD 
time series, different radiosonde hygrometers have different sensitivities and response times that often lead to different measurement errors under wet (e.g., when exiting from clouds) and dry conditions, even in recent years (Dai et al. 2011). For example, at U.S. stations, several types of radiosondes have been used since the early 1990s; the newer ones tend to have more very dry reports $\left(\mathrm{DPD} \leq 25^{\circ} \mathrm{C}\right)$. The overall effect is that the occurrence frequency for a given DPD bin may change because of changes in the radiosonde types. Accepting the additional dry reports as true observations would result in spurious downward HRH frequency trends since the 1980s. In summary, the discontinuities in the humidity dataset could not contaminate the finding that $\mathrm{HRH}$ frequencies have increased in the lower-to-middle troposphere over China.

\section{Conclusions}

To evaluate the changes in the frequencies of high relative humidity (HRH), HRH frequency trends from the ground level to the midtroposphere from 1979 to 2012 were examined over China. The results show that, at the ground level, there are more decreasing trends than increasing trends, with decreasing trends dominating in southeastern China (northern China) in spring (summer); for autumn and winter, increasing trends and decreasing trends are mixed and randomly distributed over China, except for northwestern China where more increasing trends occur in autumn. In the lower troposphere (850 and $700 \mathrm{hPa}$ ), except for southeastern China in spring, positive HRH frequency trends prevail over China during four seasons. In the midtroposphere (500 and $400 \mathrm{hPa}$ ), increasing trends prevail over China in spring, summer, and autumn. These results were also examined using data that excluded rainy days; the results were more evident as a result of an increase in the percentage of stations exhibiting positive trends from spring to autumn, particularly at 850 and $700 \mathrm{hPa}$, compared to the results derived using the original data. In addition, the percentages of stations exhibiting positive trends at 0000 and 1200 UTC in the lower and middle troposphere were compared. The percentage of stations exhibiting positive trends at 1200 UTC exceeds that for 0000 UTC in all four seasons. Moreover, the increasing $\mathrm{HRH}$ frequencies in the lower-to-middle troposphere revealed by the homogenized humidity dataset are partially supported by changes in low-tomiddle cloud amounts. Increasing low-to-middle cloud amount trends from spring to autumn are observed over northeastern, southwestern, and northwestern China and are consistent with the increasing HRH frequency found in these areas.
The HRH frequency trends in the lower and middle troposphere were calculated for six reanalysis datasets: CFSR, ERA-Interim, JRA-55, MERRA, NCEP-1, and NCEP-2. The upward HRH frequency trends obtained using the homogenized humidity dataset were revealed in certain seasons and for certain regions. For example, there are increasing trends observed over northwestern China in summer and autumn in the midtroposphere for the two data types. Meanwhile, the reanalysis datasets reproduced well the observed shapes of vertical distribution of HRH frequency trend during spring, summer and autumn; in most cases, HRH frequency trends increase from 850 to 700 or $500 \mathrm{hPa}$ and then decrease at $400 \mathrm{hPa}$ in the two data types. During winter most of the reanalysis datasets show an increasing value of $\mathrm{HRH}$ frequency trend from 850 to $400 \mathrm{hPa}$, but in the homogenized humidity dataset, the trends are positive at 850 and $700 \mathrm{hPa}$ and nearly zero at $500-400 \mathrm{hPa}$. In addition, some reanalysis datasets present increasing trends in medium cloud amount over certain regions during summer and autumn, which supports the increasing trends in low-to-middle cloud amount in observations and implies the increasing HRH frequencies revealed by the homogenized humidity dataset.

It should be noted that the reanalysis datasets cannot better reproduce the spatial and vertical variations in HRH frequency trend over China as observed from the homogenized humidity dataset. This inconsistency is likely a consequence of poor agreements in $\mathrm{HRH}$ frequency time series between the two data types on a long-term time scale, particularly after the mid-1990s. However, the reanalysis datasets show good performance to reproduce the time series of HRH frequency derived from the homogenized humidity dataset on an interannual time scale (long-term trends are excluded from the data). Among the reanalysis datasets, NCEP-1 and NCEP-2 have a relatively weak correlation with the homogenized humidity dataset on the interannual time scale as compared to the other reanalysis datasets. Thus, we have higher confidence in the ability of the reanalysis datasets to accurately simulate the interannual changes in HRH frequency in the lower and middle troposphere over China. And the uncertainties in long-term trends from the reanalysis datasets should be considered for future studies.

The aforementioned analyses suggest that increases in the mean RH and low-to-middle cloud amount may play important roles in influencing the upward HRH frequency trends in the lower and middle troposphere over China. The RH increase could be a result of the substantial increase in specific humidity in recent decades. Global warming is thought to be an important reason for the increase in specific humidity (Zhao et al. 2012). Moreover, atmospheric water vapor has been reportedly 
increasing in the real world, which is partially due to increases in greenhouse gases (e.g., Zhai and Eskridge 1997; Trenberth et al. 2005; Dai 2006). Regarding the increase in cloud amount, it is affected not only by atmospheric structure and water vapor content but also by cloud microphysical processes. Both observational evidence and modeling results show that more aerosol particles in the atmosphere may increase cloud droplet numbers and decrease cloud droplet size, which may change the lifetime of clouds and suppress precipitation (Stevens and Feingold 2009; Qian et al. 2010; Bister and Kulmala 2011). The intense human activities over China have led to substantial aerosol emissions, making China one of the heaviest sources of anthropogenic air pollutants since the early 1980s (Gong et al. 2014). Therefore, it is interesting to examine whether the increasing trend in $\mathrm{HRH}$ frequency in the lower and middle troposphere over China is related to local anthropogenic aerosols through cloud-aerosol interactions. To solve this issue, examining the trends in HRH frequency in the troposphere over other regions, such as Europe and North America, is desirable and can indirectly verify this issue. This investigation is beyond the scope of this paper and will be clarified in future analyses.

Acknowledgments. We thank Associate Professor Aiguo Dai (University at Albany, State University of New York, Albany, New York) for providing the homogenized humidity data and for insightful advice. This research was supported by the Chinese Ministry of Science and Technology through the National Basic Research Program of China (2012CB955401 and 2012CB956203). Rui Mao was supported by the Fundamental Research Funds for the Central Universities (Grant 2012LYB44) and the National Natural Science Foundation of China (41321001 and 41571039). Jing Yang was supported by the National Natural Science Foundation of China (41375003) and State Key Laboratory of Earth Surface Processes and Resource Ecology (Grant 2014-ZY-04).

\section{REFERENCES}

Andersson, E., and Coauthors, 2007: Analysis and forecast impact of the main humidity observing systems. Quart. J. Roy. Meteor. Soc., 133, 1473-1485, doi:10.1002/qj.112.

Bao, X., and F. Zhang, 2013: Evaluation of NCEP-CFSR, NCEPNCAR, ERA-Interim, and ERA-40 reanalysis datasets against independent sounding observations over the Tibetan Plateau. J. Climate, 26, 206-214, doi:10.1175/JCLI-D-12-00056.1.

Bengtsson, L., and Coauthors, 2007: The need for a dynamical climate reanalysis. Bull. Amer. Meteor. Soc., 88, 495-501, doi:10.1175/BAMS-88-4-495.

Bister, M., and M. Kulmala, 2011: Anthropogenic aerosols may have increased upper tropospheric humidity in the 20th century. Atmos. Chem. Phys., 11, 4577-4586, doi:10.5194/ acp-11-4577-2011.
Cai, M., J. Ou, Y. Zhou, Q. Yang, and Z. Cai, 2014: Discriminating cloud area by using L-band sounding data (in Chinese). Chin. J. Atmos. Sci., 38, 213-222.

Chakraborty, S., and A. Maitra, 2012: A comparative study of cloud liquid water content from radiosonde data at a tropical location. Int. Geosci., 3, 44-49, doi:10.4236/ijg.2012.31006.

Dai, A., 2006: Recent climatology, variability, and trends in global surface humidity. J. Climate, 19, 3589-3606, doi:10.1175/ JCLI3816.1.

_ J. Wang, P. W. Thorne, D. E. Parker, L. Haimberger, and X. L. Wang, 2011: A new approach to homogenize daily radiosonde humidity data. J. Climate, 24, 965-991, doi:10.1175/ 2010JCLI3816.1.

Dee, D. P., 2005: Bias and data assimilation. Quart. J. Roy. Meteor. Soc., 131, 3323-3343, doi:10.1256/qj.05.137.

_ , and S. Uppala, 2009: Variational bias correction of satellite radiance data in the ERA-Interim reanalysis. Quart. J. Roy. Meteor. Soc., 135, 1830-1841, doi:10.1002/qj.493.

_ , and Coauthors, 2011: The ERA-Interim reanalysis: Configuration and performance of the data assimilation system Quart. J. Roy. Meteor. Soc., 137, 553-597, doi:10.1002/qj.828.

Dessler, A. E., and S. M. Davis, 2010: Trends in tropospheric humidity from reanalysis systems. J. Geophys. Res., 115, D19127, doi:10.1029/2010JD014192.

Ebita, A., and Coauthors, 2011: The Japanese 55-year Reanalysis "JRA-55": An interim report. SOLA, 7, 149-152, doi:10.2151/ sola.2011-038.

Endo, N., B. Ailikun, and T. Yasunari, 2005: Trends in precipitation amounts and the number of rainy days and heavy rainfall events during summer in China from 1961 to 2000. J. Meteor. Soc. Japan, 83, 621-631, doi:10.2151/jmsj.83.621.

Gong, D.-Y., W. Wang, Y. Qian, W. Bai, Y. Guo, and R. Mao, 2014: Observed holiday aerosol reduction and temperature cooling over East Asia. J. Geophys. Res. Atmos., 119, 63066324, doi:10.1002/2014JD021464.

Haag, W., B. Kärcher, J. Ström, A. Minikin, U. Lohmann, J. Ovarlez, and A. Stohl, 2003: Freezing thresholds and cirrus cloud formation mechanisms inferred from in situ measurements of relative humidity. Atmos. Chem. Phys., 3, 1791-1806, doi:10.5194/acp-3-1791-2003.

Hosseinzadeh Talaee, P., T. A. A. Sabziparvar, and H. Tabari, 2012: Observed changes in relative humidity and dew point temperature in coastal regions of Iran. Theor. Appl. Climatol., 110, 385-393, doi:10.1007/s00704-012-0630-1.

Kalnay, E., and Coauthors, 1996: The NCEP/NCAR 40-Year Reanalysis Project. Bull. Amer. Meteor. Soc., 77, 437-471, doi:10.1175/1520-0477(1996)077<0437:TNYRP>2.0.CO;2.

Kanamitsu, M., W. Ebisuzaki, J. Woollen, S.-K. Yang, J. J. Hnilo, M. Fiorino, and G. L. Potter, 2002: NCEP-DOE AMIP-II Reanalysis (R-2). Bull. Amer. Meteor. Soc., 83, 1631-1643, doi:10.1175/BAMS-83-11-1631.

Kistler, R., and Coauthors, 2001: The NCEP-NCAR 50-Year Reanalysis: Monthly means CD-ROM and documentation. Bull. Amer. Meteor. Soc., 82, 247-267, doi:10.1175/ 1520-0477(2001)082<0247:TNNYRM > 2.3.CO;2.

McCarthy, M. P., P. W. Thorne, and H. A. Tichner, 2009: An analysis of tropospheric humidity trends from radiosondes. J. Climate, 22, 5820-5838, doi:10.1175/ 2009JCLI2879.1.

Paltridge, G., A. Arking, and M. Pook, 2009: Trends in middle- and upper-level tropospheric humidity from NCEP reanalysis data. Theor. Appl. Climatol., 98, 351-359, doi:10.1007/ s00704-009-0117-x. 
Price, J., and R. Wood, 2002: Comparison of probability density functions for total specific humidity and saturation humidity, and consequences for cloud parameterization. Quart. J. Roy. Meteor. Soc., 128, 2059-2072, doi:10.1256/ 003590002320603539.

Qian, T., A. Dai, K. E. Trenberth, and K. W. Oleson, 2006: Simulation of global land surface conditions from 1948 to 2002. Part I: Forcing data and evaluations. J. Hydrometeor., 7, $953-$ 975, doi:10.1175/JHM540.1.

Qian, Y., D. Gong, and R. Leung, 2010: Light rain events change over North America, Europe and Asia for 1973-2009. Atmos. Sci. Lett., 11, 301-306, doi:10.1002/asl.298.

Remsberg, E. E., and Coauthors., 2000: Instrumentation and data sets. SPARC assessment of upper tropospheric and stratospheric water vapour, SPARC Rep. 2, WCRP-113, WMO/TD 1043, 33-36.

Rienecker, M. M., and Coauthors, 2011: MERRA: NASA's ModernEra Retrospective Analysis for Research and Applications. J. Climate, 24, 3624-3648, doi:10.1175/JCLI-D-11-00015.1.

Ruzmaikin, A., H. H. Aumann, and E. M. Manning, 2014: Relative humidity in the troposphere with AIRS. J. Atmos. Sci., 71, 2516-2533, doi:10.1175/JAS-D-13-0363.1.

Saha, S., and Coauthors, 2010: The NCEP Climate Forecast System Reanalysis. Bull. Amer. Meteor. Soc., 91, 1015-1057, doi:10.1175/ 2010BAMS3001.1.

Simmons, A. J., K. M. Willett, P. D. Jones, P. W. Thorne, and D. P. Dee, 2010: Low-frequency variations in surface atmospheric humidity, temperature, and precipitation: Inferences from reanalyses and monthly gridded observational datasets. J. Geophys. Res., 115, D01110, doi:10.1029/2009JD012442.

—, P. Poli, D. P. Dee, P. Berrisford, H. Hersbach, S. Kobayashi, and C. Peubey, 2014: Estimating low-frequency variability and trends in atmospheric temperature using ERA-Interim. Quart. J. Roy. Meteor. Soc., 140, 329-353, doi:10.1002/qj.2317.

Stevens, B., and G. Feingold, 2009: Untangling aerosol effects on clouds and precipitation in a buffered system. Nature, 461, 607-613, doi:10.1038/nature08281.

Sundqvist, H., 1978: A parameterization scheme for nonconvective condensation including prediction of cloud water content. Quart. J. Roy. Meteor. Soc., 104, 677-690, doi:10.1002/qj.49710444110.

Trenberth, K. E., J. Fasullo, and L. Smith, 2005: Trends and variability in column-integrated atmospheric water vapor. Climate Dyn., 24, 741-758, doi:10.1007/s00382-005-0017-4.

van Wijngaarden, W. A., and L. A. Vincent, 2004: Trends in relative humidity in Canada from 1953-2003. 15th Symp. on Global Change and Climate Variations, Seattle, WA, Amer. Meteor. Soc., JP2.3. [Available online at https://ams.confex. com/ams/84Annual/techprogram/paper_70289.htm.]
Wang, A., and X. Zeng, 2012: Evaluation of multireanalysis products with in situ observations over the Tibetan Plateau. J. Geophys. Res., 117, D05102, doi:10.1029/2011JD016553.

Wang, J., and W. B. Rossow, 1995: Determination of cloud vertical structure from upper-air observations. J. Appl. Meteor., 34, 2243-2258, doi:10.1175/1520-0450(1995)034<2243: DOCVSF $>2.0 . \mathrm{CO} ; 2$.

and Y. Zhang, 2000: Cloud vertical structure and its variations from a 20-yr global rawinsonde dataset. J. Climate, 13, 30413056, doi:10.1175/1520-0442(2000)013<3041:CVSAIV>2.0.CO;2.

Webster, P. J., and G. L. Stephens, 1984: Cloud radiation interaction and the climate problem. The Global Climate, J. Houghton, Ed., Cambridge University Press, 63-78.

Willett, K. M., P. D. Jones, N. P. Gillett, and P. W. Thorne, 2008: Recent changes in surface humidity: Development of the HadCRUH dataset. J. Climate, 21, 5364-5383, doi:10.1175/ 2008JCLI2274.1.

Wright, J. S., A. Sobel, and J. Galewsky, 2010: Diagnosis of zonal mean relative humidity changes in a warmer climate. J. Climate, 23, 4556-4569, doi:10.1175/2010JCLI3488.1.

Xie, B., Q. Zhang, and Y. Ying, 2011: Trends in precipitable water and relative humidity in China: 1979-2005. J. Appl. Meteor. Climatol., 50, 1985-1994, doi:10.1175/2011JAMC2446.1.

Xu, X., 2012: Spatiotemporal variation of total cloud and low cloud over China (in Chinese). Meteor. Mon., 38, 90-95.

Zhai, P., and R. E. Eskridge, 1997: Atmospheric water vapor over China. J. Climate, 10, 2643-2652, doi:10.1175/ 1520-0442(1997)010<2643:AWVOC >2.0.CO;2.

Zhang, J., H. Chen, Z. Li, X. Fan, L. Peng, Y. Yu, and M. Cribb, 2010: Analysis of cloud layer structure in Shouxian, China using RS92 radiosonde aided by $95 \mathrm{GHz}$ cloud radar. J. Geophys. Res., 115, D00K30, doi:10.1029/2010JD014030.

Zhang, R., W. Yan, D. Han, and S. Yang, 2012: Determination of cloud vertical structure and analysis of its distribution based on RS92 radiosonde data (in Chinese). Remote Sens. Technol. Appl., 27, 231-236. [English abstract available online at http:// www.rsta.ac.cn/EN/abstract/abstract1812.shtml.]

Zhao, T., A. Dai, and J. Wang, 2012: Trends in tropospheric humidity from 1970 to 2008 over China from a homogenized radiosonde dataset. J. Climate, 25, 4549-4567, doi:10.1175/ JCLI-D-11-00557.1.

Zhou, Y., and J. J. Ou, 2010: The method of cloud vertical structure analysis using rawinsonde observation and its applied research (in Chinese). Meteor. Mon., 36, 50-58.

Zong, X., P. Wang, and X. Xia, 2013: Variability and long-term trend of total cloud cover in China derived from ISCCP, ERA40, CRU3, and ground station datasets. Atmos. Oceanic Sci. Lett., 6, 133-137, doi:10.3878/j.issn.1674-2834.12.0100. 